\title{
SUPLEMENTAÇÃO DE VITAMINA C NA REVERSÃO SEXUAL DE TILÁPIA DO NILO (Oreochromis niloticus)
}

\section{GLÁUCIO NOGUEIRA TOYAMA}

Engenheiro Agrônomo

Orientador: Prof. Dr. José Eurico Possebon Cyrino

Dissertação apresentada à Escola Superior de Agricultura "Luiz de Queiroz", Universidade de São Paulo, para obtenção do título de Mestre em Agronomia, Área de Concentração: Ciência Animal e Pastagens.

\section{PIRACICABA}

Estado de São Paulo - Brasil

Junho - 1999 


\section{Dados Internacionais de Catalogação na Publicação (CIP) \\ DIVISÃo DE BIBLIOTECA E DOCUMENTAÇÃO - Campus "Luiz de Queiroz"/USP}

Toyama, Gláucio Nogueira

Suplementação de vitamina $\mathrm{C}$ na reversão sexual de tilápia do nilo (Oreochromis niloticus) / Gláucio Nogueira Toyama. - - Piracicaba, 1999.

$46 \mathrm{p}$.

Dissertação (mestrado) - - Escola Superior de Agricultura Luiz de Queiroz, 1999. Bibliografia.

1. Dieta animal 2. Nutrição animal 3. Reversão sexual 4. Tilápia-do-nilo 5. Vitamina C I. Titulo

CDD 639.31 
À minha família que sempre me apoiou,

minha mãe,

\section{Maria Madalena dos Santos Nogueira,}

e meus irmãos,

Glauber, (in memorian), Glenn e Seheilen,

À minha querida esposa,

\section{Carolina Ribeiro Toyama}

que esteve ao meu lado nestes últimos três anos e me deu muita força, 


\section{AGRADECIMENTOS}

Pelo apoio e auxilio na realização de mais esta etapa na minha vida profissional, gostaria de agradecer especialmente às seguintes pessoas:

Ao Prof. Dr. José Eurico Possebon Cyrino pela sua orientação e dedicação durante todo o curso de mestrado e pela inestimável amizade;

Ao Prof. Dr. Leonard Lovshin pela valiosa colaboração na implantação e na condução do projeto de pesquisa;

Ao Prof. Dr. José Eduardo Corrente do Departamento de Ciências Exatas da Escola Superior de Agricultura "Luiz de Queiroz", pelo grande auxilio na análise estatística dos dados da dissertação;

Aos amigos Mário de Moraes Rossetti e Anamania Germano Ribeiro pelo inestimável apoio e compreensão;

Aos colegas de curso Ricardo Franklin de Mello, Mônica Accaui Marcondes Moura, Ivan Vieira e Ana Maria Barreto de Menezes Sampaio, pela amizade e apoio;

A todos os estagiários do Setor de Piscicultura do Departamento de Zootecnia da Escola Superior de Agricultura 'Luiz de Queiroz”, pela ajuda;

À bibliotecária Eliana Maria Garcia Sabino pela revisão e correções na bibliografia;

A todos os professores do Departamento de Produção Animal da Escola Superior de Agricultura "Luiz de Queiroz";

Ao Conselho de Nacional de Desenvolvimento Científico e Tecnológico - CNPq, pela concessão da bolsa de estudos;

À Sansuy SA Indústria de Plásticos e à Piscicultura Paulista pelo apoio material na forma de doação dos "hapas" e do material biológico utilizados no experimento;

A todos aqueles que conosco contribuíram de alguma forma nestes anos passados do curso de mestrado. 


\section{SUMÁRIO}

Página

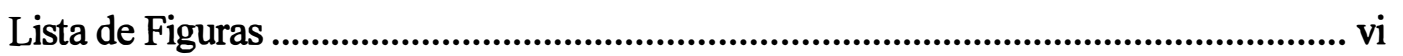

Lista de Tabelas.............................................................................................. vii

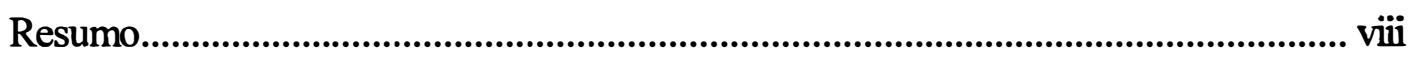

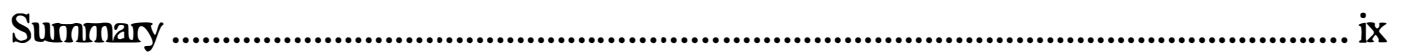

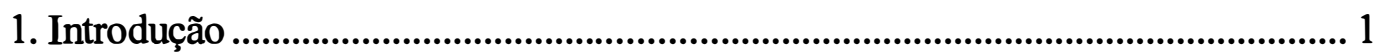

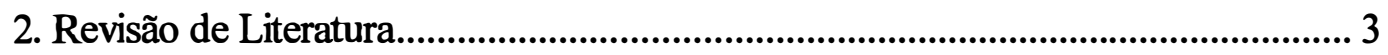

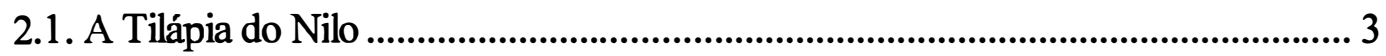

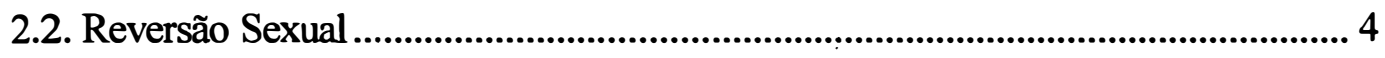

2.3. Vitamina $C$ na Nutrição de Peixes ...................................................................... 7

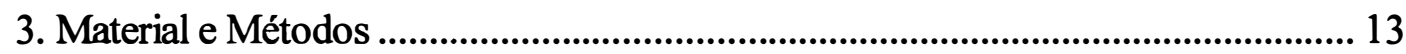

3.1. Unidades Experimentais ..................................................................................... 13

3.2. Material Biológico - Pós-larvas........................................................................ 14

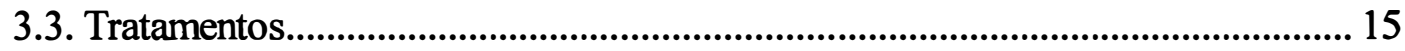

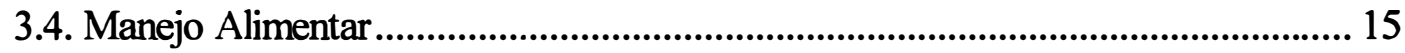

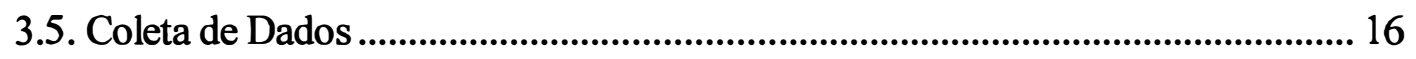

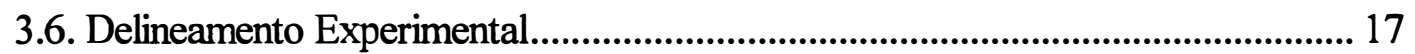

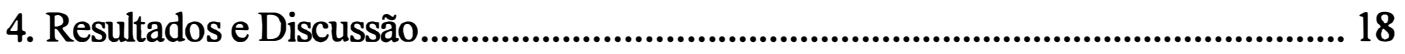

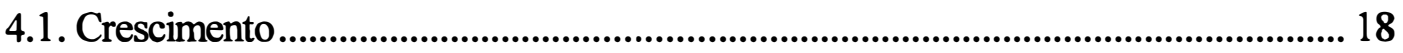

4.2. Sobrevivência e Reversão Sexual ......................................................................... 25

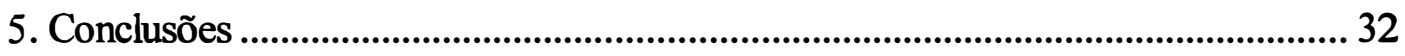

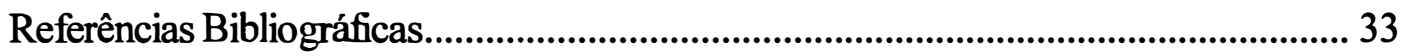

Apêndice.................................................................................................................... 39 


\section{LISTA DE FIGURAS}

Página

1. Gráfico de dispersão e equação de regressão polinomial para peso final, na fase de reversão sexual da tilápia do Nilo (30 dias) 22

2. Gráfico de dispersão e equação de regressão polinomial para comprimento total final, na fase de reversão sexual da tilápia do Nilo (30 dias)

3. Gráfico de dispersão e equação de regressão polinomial para sobrevivência final, na fase de reversão sexual da tilápia do Nilo (30 dias) 


\section{LISTA DE TABELAS}

Página

1. Valores médios estimados de peso $(\mathrm{P})$ e comprimento total (CT) obtidos nas biometrias realizadas durant ea fase de reversão sexual da tilápia do Nilo

2. Análise da variância para variável peso

3. Decomposição da int eraçãotratamento $\mathrm{x}$ dat apara variável peso 20

4. Análise da variância para variável comprimento total 20

5. Decomposição da int eraçãotratame nto $x$ data para variável comprimento total

6. Resultados do T este de T ukey para comparação de médias das variáveis peso e comprimento

7. Porcentagem média estimada de sobrevivência (S\%) e porcentagem média de reversão sexual (RS\%) por tratamento ao final da fase de reversão sexual de tilápia do Nilo 25

8. Resultados da análise da variância para a variável reversão sexual.

9. Resultados da análise da variância para a variável sobreviv ência.

10. Resultados do Teste de T ukey para comparação de médias das variáveis reversão sexual e sobrevivência 


\title{
SUPLEMENTAÇÃO DE VITAMINA C NA REVERSÃO SEXUAL DE TILÁPIA DO NILO (Oreochromis niloticus)
}

\author{
Autor: Gláucio Nogueira Toyama \\ Orientador: Prof. Dr. José Eurico Possebon Cyrino
}

\section{RESUMO}

O objetivo do estudo foi avaliar o efeito de oito níveis de suplementação de vitamina C (ácido ascórbico) nas dietas $(0 ; 50 ; 100 ; 200 ; 400 ; 600 ; 800$ e $1.000 \mathrm{mg} / \mathrm{kg}$ da dieta), no processo de reversão sexual da tilápia do Nilo (Oreochromis niloticus) (T0, T50, T100, T200, T400, T600, T800 e T1000; $n=3$ ). Cada unidade experimental foi composta por 600 pós-larvas estocadas em "hapas" de $0,08 \mathrm{~m}^{3}$. Os parâmetros avaliados foram: ganho de peso $(\mathrm{mg})$ e incremento em comprimento $(\mathrm{mm})$ aos $0,10,20$ e 30 dias de tratamento; porcentagem da sobrevivência final (S\%) e porcentagem de reversão sexual (RS\%). Os resultados das biometrias indicaram que a partir do dia 20 os indivíduos apresentaram diferença significativa para peso e comprimento $(\mathrm{P}>0,0001)$. Os resultados do teste de comparação de médias (Tukey) mostraram que em relação ao ganho de peso, os melhores resultados foram obtidos com suplementação acima de 800 mg de vitamina $\mathrm{C} / \mathrm{kg}$ da dieta, e para comprimento total, níveis de inclusão acima de 400 $\mathrm{mg} / \mathrm{kg}$; os piores desempenhos observados estavam em níveis abaixo de $50 \mathrm{mg} / \mathrm{kg}$. Com relação à S\%, foi verificado que a suplementação de vitamina $\mathrm{C}$ acima de $200 \mathrm{mg} / \mathrm{kg}$ proporciona médias semelhantes e o tratamento sem adição de vitamina $\mathrm{C}$ proporciona os piores resultados. Em relação à RS\%, não foram encontradas diferenças estatisticamente significativas entre os tratamentos $(\mathrm{P}>0,9993)$, indicando que a suplementação de vitamina $\mathrm{C}$ na dieta não afeta a taxa de reversão sexual da tilápia do Nilo. As equações de regressão polinomial para peso, comprimento total e sobrevivência, indicam que os níveis de suplementação de vitamina $\mathrm{C}$ na dieta para obtenção dos melhores resultados foram, respectivamente, 859,$5 ; 765,0$ e $685,7 \mathrm{mg}$ de vitamina $\mathrm{C}$ por $\mathrm{kg}$ da dieta. 


\title{
VITAMIN C SUPPLEMENTATION ON DIETS FOR SEX REVERSAL OF NILE TILAPIA (Oreochromis niloticus)
}

\author{
Author: Gláucio Nogueira Toyama \\ Adviser: Prof. Dr. José Eurico Possebon Cyrino
}

\section{SUMMARY}

To evaluate the effects of vitamin C supplementation $(0 ; 50 ; 100 ; 200 ; 400$; $600 ; 800 ; 1,000 \mathrm{mg} / \mathrm{kg}$ of diet) on sex reversal diets for Nile tilapia Oreochromis niloticus, groups of 600 larvae were stocked in $24,0,08-\mathrm{m}^{3}$ hapas and fed for 30 days with hormone-treated feeds containing one of the different supplementation levels (T0, T50, T100, T200, T400, T600, T800, T1000; $\mathrm{n}=3$ ). Weight gain (mg) and growth in total length $(\mathrm{mm})$ were evaluated at days $0,10,20$ and 30 of the experimental period; survival rate (S\%) and sex reversal rate (SR\%) were determined at the end of the experimental period. Weight gain and growth in length became significantly different only after day $20(\mathrm{P}>0.0001)$. Best results for weight gain were attained with supplementation levels higher than $800 \mathrm{mg} / \mathrm{kg}$; best results for growth in length were attained with supplementation levels higher than $400 \mathrm{mg} / \mathrm{kg}$. Growth and weight gain performance were very poor in treatments T0 and T50. Levels of supplementation higher than T200 do not lead to better survival rates, and sex reversal rates were not significantly affected by vitamin $\mathrm{C}$ supplementation of sex reversal diets $(\mathrm{P}>0.9993)$. Optimal values of vitamin C supplementation of sex reversal diets for Nile tilapia derived from polinomial regression analysis procedures are: 859.5 for weight gain; 765.0 for growth in length, and 685.7 for survival rate. 


\section{INTRODUÇÃO}

O suprimento de ovos e alevinos de qualidade e em quantidades adequadas é de fundamental importância na consolidação de uma cadeia agro-industrial na aquicultura. A obtenção de um produto de boa qualidade é diretamente relacionada com o nível de desenvolvimento tecnológico da área. Os fatores relacionados às características das espécies, ao sistema de produção e à alimentação e nutrição são as principais determinantes no sucesso da atividade.

De maneira geral, os custos associados às práticas de manejo alimentar $\mathrm{e}$ nutrição em piscicultura representam mais de $50 \%$ do custo total de produção em sistemas semi-intensivos, chegando a $80 \%$ em sistemas superintensivos. Alimentos mal formulados são mal aproveitados pelos peixes e podem causar sérios impactos ambientais, reduzindo o potencial de produção. Deste modo, pesquisas sobre a nutrição e determinação de níveis corretos de exigências nutricionais dos peixes constituem-se em uma importante ferramenta de desenvolvimento da piscicultura comercial, objetivando uma produção econômica e racional.

A tilápia do Nilo, embora sendo uma espécie introduzida, é sem dúvida uma das principais espécies da fauna aquática brasileira com potencial para alicerçar a expansão da piscicultura industrial. Esta espécie está devidamente adaptada às nossas condições climáticas e sua criação é feita a partir de um pacote tecnológico muito bem definido. Em adição, suas características zootécnicas e a alta qualidade de sua carne tornam-na apta ao processamento industrial e muito bem aceita pelo mercado consumidor.

Este trabalho visou observar os efeitos da suplementação de vitamina $\mathrm{C}$ no 
tratamento de reversão sexual de tilápia do Nilo. Esta suplementação nutricional é de grande importância nas fases iniciais de vida e do ciclo de produção da espécie, sendo fator preponderante na sustentabilidade das criações em regime intensivo, onde o uso de populações com baixa taxa de reversão sexual ou mal nutridas pode dificultar o manejo e comprometer a produtividade e a lucratividade dos sistemas. 


\section{REVISÃO DE LITERATURA}

\subsection{A Tilápia do Nilo}

A tilápia do Nilo, Oreochromis niloticus, tem sua origem no continente Africano e na Palestina, mas já está amplamente distribuída no mundo (Philippart \& Ruwet, 1982; Lim, 1988; Popma \& Lovshin, 1994). Em função da sua rusticidade, aceitação de uma variedade de alimentos e bom desempenho produtivo, a espécie passou rapidamente a ocupar distantes e diferentes bacias hidrográficas, tanto em ambiente natural como em viveiros para produção (Lim, 1988; Popma \& Lovshin, 1994).

Em função desta grande distribuição e da qualidade de sua carne, este peixe se tornou uma das principais espécies da aquicultura mundial (Bardach et al. 1972; Lim, 1988; Pullin, 1991). A criação da tilápia do Nilo no Brasil é praticada em sistemas e níveis de produção os mais diversos, desde o extensivo até o super-intensivo, tanto em viveiros como em tanques-rede ou "raceways".

A reprodução da espécie é caracterizada por desovas parciais. A tilápia do Nilo pode reproduzir-se durante o ano todo se a temperatura média da água permanecer acima de $25^{\circ} \mathrm{C}$ (Hepher \& Pruginin, 1981; Philipart \& Ruwet, 1982; Lim, 1988; Meade, 1989; Popma \& Green, 1990; Popma \& Lovshin, 1994). As fềmeas de tilápia apresentam maturidade sexual precoce, podendo apresentar a primeira desova por volta dos 3 até os 6 meses de idade, ou com peso acima de $20 \mathrm{~g}$ (Bardach et al. 1972, Hepher \& Pruginin, 1981; Jalabert \& Zohar, 1982; Lim, 1988; Popma \& Lovshin, 1994; Green et al. 1997).

Durante a fase de reprodução, os peixes do gênero Oreochromis sp exercem cuidado parental com os ovos, e posteriormente com as larvas, até a absorção do saco 
vitelínico. No caso da tilápia do Nilo, as fềmeas protegem seus ovos e suas larvas dentro da sua cavidade bucal contra os predadores por 14 a 23 dias, conforme a temperatura média da água (Bardach et al. 1972; Lagler et al. 1977; Hepher \& Pruginin, 1981; Jalabert \& Zohar, 1982; Philipart \& Ruwet, 1982; Trewavas, 1982; Popma \& Green, 1990; Pullin, 1991; Popma \& Lovshin, 1994).

O hábito alimentar da tilápia do Nilo é fitoplanctófago, o que pode ser observado pelos aspectos morfológicos envolvidos do sistema digestivo. Os rastros e filamentos branquiais são numerosos, longos e apresentam-se bem agrupados, permitindo ótima eficiência na filtragem (Bardach et al. 1972; Bowen, 1982; Steffens, 1989; Popma $\&$ Lovshin, 1994). O comprimento do seu sistema digestivo chega a alcançar 10 a 15 vezes o comprimento corporal, o que aumenta o tempo de digestão e absorção dos nutrientes do alimento natural (Trewavas, 1982). Entretanto, em criação, a espécie aceita os mais variados alimentos.

As exigências nutricionais das tilápias na fase final do crescimento variam de $25 \%$ à $35 \%$ de proteína bruta $(\mathrm{PB})$ e $3.000 \mathrm{kcal}$ de energia digestível $(\mathrm{ED})$ por quilo da dieta A exemplo da maioria das espécies de peixe utilizadas em piscicultura intensiva, níveis adequados de ED nas dietas de tilápias proporcionam a economia de proteína e maximizam a taxa de crescimento. A criação de tilápias em regimes intensivos exige o uso de dietas completas, e quando as dietas não atendem os níveis exigidos pelos peixes e disponibilidade de nutrientes de fontes naturais é baixa, os sintomas de deficiências nutricionais aparecem rápida e freqüentemente em criações comerciais (Lim, 1988; NRC, 1993; Santiago \& Reyes, 1993; Popma \& Lovshin, 1994).

\subsection{Reversão Sexual}

A criação de tilápias para o mercado consumidor em qualquer sistema ou tipo de cultivo apresenta-se mais vantajosa quando praticada a partir de populações monosexo masculinas. Fêmeas de tilápia apresentam taxas de ganho de peso e conversão alimentar inferiores àquelas dos machos. Este fato, aliado à precocidade sexual, faz com que as 
fềmeas apresentem respostas menos eficientes em relação à sua produtividade quando comparadas aos machos (Lim, 1988; Lahav \& Lahav, 1990; Popma \& Lovshin, 1994). O desvio de energia para a formação dos óvulos e o período de cuidado parental com a incubação de ovos e proteção das larvas na cavidade bucal, dificulta a alimentação das fềmeas (Hepher \& Pruginin, 1981; Little et al. 1993). Além disso, a reprodução descontrolada nos sistemas de produção promove aumento exagerado da população de peixes no sistema de criação e, consequentemente, aumenta a competição por alimentos e prejudica a qualidade de água no ambiente, o que reduz ou prejudica o crescimento dos peixes.

Desta forma, dentro do pacote tecnológico que envolve a produção de tilápias, a obtenção de populações monosexo é uma das etapas do cultivo. Dentre as possíveis técnicas de obtenção de populações monosexo temos a reversão sexual, a hibridização, a seleção manual e a utilização de super machos.

A hibridização para obtenção de gerações monosexo consiste no cruzamento dirigido de espécies com mecanismos genéticos diferenciados de determinação sexual, como por exemplo machos de Oreochromis urolepis hornorum com fềmeas de Oreochromis niloticus ou machos de Oreochromis aureus com fềmeas de Oreochromis niloticus. Estes cruzamentos produzem populações com $100 \%$ ou 85 à $99 \%$ de machos, respectivamente (Popma \& Lovshin, 1994). Este processo exige um controle genético meticuloso e uma manutenção eficiente do plantel de reprodutores. Em adição, incompatibilidade reprodutiva parcial entre as espécies pode reduzir a produtividade de larvas (Pruginin, et al. 1975; Lim, 1988; Popma \& Lovshin, 1994; Wohlfarth, 1994; Green et al. 1997).

A seleção manual para obtenção de população monosexo baseia-se na separação manual de machos e de fềmeas na fase juvenil, identificados pela observação das papilas genitais dos indivíduos (Lim, 1988; Popma \& Lovshin, 1994; Green et al. 1997). Assumindo que numa população normal a proporção entre machos e fềmeas seja 1:1, a metade composta por fềmeas será descartada apenas na fase juvenil. Anteriormente a este período, todos os peixes são mantidos no sistema de produção para crescer, 
ocupando espaço, consumindo alimento e recursos humanos, onerando o sistema de produção, o que consiste uma grande desvantagem do método. Em adição, este sistema demanda mão de obra qualificada e muito bem treinada, e está sujeito a uma grande margem de erro.

A produção de lotes monosexo através da obtenção e uso de super machos é uma técnica que apresenta diversas limitações e muitos estudos deverão ser investigados para adequação do método. Está técnica consiste na reversão sexual dos reprodutores para o sexo feminino, deste lote são utilizadas as fêmeas geneticamente masculinas XY para cruzamento com machos normais $\mathrm{XY}$, com isto teremos uma composição populacional de $25 \%$ fềmeas XX, $50 \%$ de machos XY e $25 \%$ de machos YY. Estes "supermachos" YY são então utilizados em cruzamentos que originam somente animais do sexo masculino (Scott et al. 1989; Popma \& Lovshin, 1994; Green et al. 1997). A grande vantagem deste procedimento está na utilização de hormônios apenas nos reprodutores. Como desvantagem temos a necessidade da realização de testes de progênie para identificar os animais YY, o que demanda muito tempo, mão de obra qualificada e recursos financeiros.

Devido a facilidade de aplicação e grande eficiência na obtenção de populações monosexo masculinas, a técnica da reversão sexual tem sido o método mais utilizado, alcançando níveis de 95 a 99\% de eficiência (Hepher \& Pruginin, 1981; Lim, 1988; Popma \& Green, 1990; Popma \& Lovshin, 1994; Pandian \& Sheela, 1995; Green et al. 1997). A reversão sexual para tilápia do Nilo consiste na administração oral de hormônio sexual masculino durante os primeiros 30 dias de vida dos peixes, fase em que estes ainda não exibem diferenciações sexuais secundárias. A duração do tratamento hormonal é determinada pelo consumo, que por sua vez varia em função da temperatura da água e do estágio de desenvolvimento dos peixes (Lim, 1988; Popma \& Lovshin, 1994; Pandian \& Sheela, 1995).

O método utiliza pós-larvas selecionadas, com no máximo $13 \mathrm{~mm}$ de comprimento total. As pós-larvas são alimentadas com uma ração pulverizada a partículas inferiores a $1 \mathrm{~mm}$, à qual é incorporado hormônio masculino (Popma \& 
Lovshin, 1994). Muitos tipos de hormônios naturais e sintéticos têm sido utilizados neste procedimento. Os melhores índices de eficiência satisfatórios na reversão de tilápias do Nilo têm sido obtidos com o emprego de 30 a $60 \mathrm{mg}$ de $17 \alpha$-metiltestosterona por quilo de ração (Lovell, 1989; Popma \& Green, 1990; Vera Cruz \& Mair, 1994; Pandian \& Sheela, 1995; Abucay \& Mair, 1997; Green et al. 1997)

Varadaraj et al. (1994) pontifica que o emprego da técnica de reversão sexual com $100 \%$ de sucesso seria possível apenas se pudesse ser feito um controle rigoroso de todos fatores que influenciam os resultados. Baixos índice de eficiência na reversão sexual se devem ao emprego de lotes de larvas não homogêneos, uso de larvas com tamanho inicial acima do recomendado, qualidade sanitária da larva, qualidade da ração composição, flutuabilidade, atrato-palatabilidade e granulometria, dose de hormônio utilizada, preparo e acondicionamento da ração, variações no manejo alimentar e na qualidade da água.

\subsection{Vitamina $\mathrm{C}$ na Nutrição de Peixes}

As vitaminas são grupos de compostos orgânicos exigidos em pequenas quantidades por peixes, para a manutenção dos processos vitais. $\mathrm{O}$ suprimento adequado de vitaminas é um fator muito importante para o desenvolvimento dos peixes. Para evitar os sintomas de deficiência e alcançar índices de desempenho satisfatórios, é necessário que os níveis de nutrientes nas rações sejam adequados para cada espécie.

O ácido ascórbico (vitamina C) é uma das vitaminas essenciais para os peixes. Os peixes, assim como alguns outros animais, não conseguem sintetizar vitamina $\mathrm{C}$ porque não apresentam a enzima $\mathrm{L}$ gulonolactona oxidase que possibilita a síntese da vitamina C a partir da glucose (NRC, 1983; Soliman et al. 1986a; Steffens, 1989; Lovell, 1989).

Esta vitamina ocorre em duas formas: uma forma redurida - ácido Lascórbico, e uma forma oxidada - ácido dehidroascórbico. A forma reduzida é mais abundante na natureza, mas as duas formas são biologicamente reversíveis. O ácido L- 
ascórbico é a forma mais ativa biologicamente de vitarnina $\mathrm{C}$, mas é também solúvel em água, termolábil e facilmente oxidada para uma forma inativa, o ácido dicetogulônico, durante o processamento e estocagem das rações, principalmente na presença de cobre e dos íons de metais pesados (Halver, 1989; Lovell, 1989; Tacon, 1991; NRC, 1993; Shiau \& Hsu, 1995). Alguns derivados ou sais do ácido ascórbico podem ser utilizados como fonte de vitamina $\mathrm{C}$ na dieta e apresentam variados graus de atividade de ascorbato. Um destes derivados, $\mathrm{L}$-ascorbato 2-sulfato, vitamina $\mathrm{C}_{2}$, é uma forma estável ao calor e pode ser prontamente convertida em ácido L-ascórbico (vitamina $\mathrm{C}_{1}$ ) pela enzima 2-sulfatase, sob demanda metabólica e controle de retroalimenatção (Halver, 1985; Soliman et al. 1986b; Steffens, 1989).

Para evitar perdas da forma ativa de ácido ascórbico, o alimento deve ser protegido de oxidação aeróbica, e qualquer alimento úmido deve ser cuidadosamente protegido de agentes oxidantes, do ar, do ferro, cobre e de outros metais, que catalisam a oxidação do ácido ascórbico para formas inativas biologicamente. Os alimentos dos peixes devem ser mantidos embalados ou congelados, e utilizados rapidamente (Halver, 1989).

Outras fontes de vitamina $\mathrm{C}$ têm sido testadas na nutrição de peixes e com resultados satisfatórios. Soliman et al. (1986a) não detectaram diferenças no peso médio final, no fator de condição, na taxa de crescimento específico, na taxa de conversão alimentar e na taxa de utilização de proteína de alevinos de tilápia do Nilo que receberam dietas suplementadas com $125 \mathrm{mg} / 100 \mathrm{~g}$ da dieta de L-ácido ascórbico, L-ácido ascórbico sódico, L-ácido ascórbico protegido por glicerídeos, L-ácido ascórbico 2sulfato de bário e ascorbil palmitato. Shiau \& Hsu (1995) demonstraram que o ascorbil-2sulfato e L-ascorbil-2-monofosfato tem atividade anti-escorbútica similar para tilápia, mas que o ascorbil-2-sulfato é menos efetivo na manutenção de máxima estocagem de ácido L-ascórbico nos tecidos.

A vitamina C é essencial para síntese de colágeno e formação de cartilagem, na formação dos dentes e dos ossos, nos reparos ósseos e na cicatrização (Halver, 1989; Lovell, 1989; Tacon, 1991; NRC, 1993). A diminuição na absorção total de cálcio nos 
tecidos induz a mobilização de cálcio dos ossos, a fim de manter a homeostase plasmática deste mineral, causando deformidades esqueléticas. A deficiência de ácido ascórbico influencia a absorção de cálcio e a síntese de colágeno pela diminuição da hidroxilação do protocolágeno, prolina e lisina (Mahajan \& Agrawal, 1980b).

O ácido ascórbico participa do metabolismo do ferro (Halver, 1985; Steffens, 1989; NRC, 1993) e da redução dos efeitos nocivos de hormônios produzidos pela glândula adrenal durante os períodos de estresse, e ainda ajuda na ativação da vitamina $\mathrm{D}$. Também age como redutor no transporte de hidrogênio (Tacon, 1991). É uma vitamina de grande importância para muitos sistemas enzimáticos de hidroxilação, como hidroxilação do triptofano, da tirosina e da prolina (Mahajan \& Agrawal, 1980b; Halver, 1985, 1989; Steffens, 1989; Tacon, 1991). O ácido ascórbico também está envolvido na desintoxicação de drogas aromáticas e na produção de esteróides adrenais (Halver, 1985; Tacon, 1991).

$\mathrm{O}$ ácido ascórbico está envolvido sinergicamente com a vitamina $\mathrm{E}$ na manutenção de antioxidantes intracelulares, na redução de radicais livres e na maturação de eritrócitos para manutenção do hematócrito normal. A vitamina $C$ também tem ação sinérgica com a vitamina $\mathrm{E}$ e o selênio na manutenção da atividade da glutadionaperoxidase superóxido-dismutase (Halver, 1989; Soliman et al. 1994; Fracalossi, 1998). A conversão de ácido fólico em ácido folânico necessita de vitamina $\mathrm{C}$ para formar a coenzima ativa. $\mathrm{O}$ ácido ascórbico é necessário na formação de frações de sulfato de condroitina e substâncias intracelulares, e é capaz de formar derivados de sulfato com características químicas muito estáveis (Lovell, 1989; Tacon, 1991).

A vitamina $\mathrm{C}$ está amplamente distribuída na natureza. Embora frutas cítricas, algas, repolho, figado e rins sejam boas reservas desta vitamina, a elaboração de dietas para peixes a partir destes alimentos exige suplementação com vitamina C (Halver, 1989; Tacon, 1991). Altos níveis de vitamina $C_{2}$ são encontrados na camada dérmica pesada de tecidos de peixes e quantidades apreciáveis estão ainda presentes nas farinhas de peixes obtidas de peixes inteiros (Halver, 1989; Tacon, 1991).

As exigências nutricionais dos peixes por vitamina $\mathrm{C}$ são influenciadas por 
vários fatores, como idade, tamanho, estado reprodutivo, estresse, entre outros (Halver, 1985; NRC, 1993). Para Lim (1988) as tilápias provavelmente têm exigências metabólicas similares a outras espécies tropicais, e apresentam os sinais clássicos de deficiência de vitamina $\mathrm{C}$ quando esta não é suplementada na ração ou na falta de alimento natural. $\mathrm{O}$ nível de inclusão de ácido ascórbico em uma dieta deve considerar a variação do material bruto, as interações entre nutrientes e não nutrientes e as perdas no processamento e estocagem. Em viveiros de terra, a tilápia pode satisfazer suas exigências nutricionais de vitamina $\mathrm{C}$ e outros micronutrientes com o alimento natural. Nitzan et al. (1996) não observaram nenhuma diferença significativa para taxa de crescimento, sobrevivência e produção em peixes alimentados com dietas suplementadas com $495 \mathrm{mg} / \mathrm{kg}$ de vitamina $\mathrm{C}$ e sem suplementação em viveiros.

Soliman et al. (1994) determinaram a exigência de $125 \mathrm{mg}$ de vitamina C/100 $\mathrm{g}$ da dieta para ótimo desenvolvimento de tilápias. Este valor equivale a uma exigência nutricional de $42 \mathrm{mg} / 100 \mathrm{~g}$ de alimento, e é relativo a $34,15 \%$ de retenção de vitamina $\mathrm{C}$ depois de processamento e estocagem das rações. Já para Popma \& Lovshin (1994) a exigência determinada para os peixes do gênero Oreochromis é de $50 \mathrm{mg} / \mathrm{kg}$ da dieta.

Shiau \& Jan (1992) determinaram que a exigência de ácido ascórbico na nutrição de juvenis de híbridos de tilápia (Oreochromis niloticus $\mathrm{X}$ O. aureus) para máximo crescimento é de $79 \mathrm{mg} / \mathrm{kg}$. Os resultados mostraram ainda que peixes alimentados com dietas suplementadas com menos que $40 \mathrm{mg} / \mathrm{kg}$ de vitamina $\mathrm{C}$ têm pior crescimento, conversão alimentar e eficiência protéica, baixos níveis de retenção hepática de ácido ascórbico e hematócrito reduzido.

No caso de reprodutores, Soliman et al. (1986b) mostraram que a inclusão de $125 \mathrm{mg}$ de ácido ascórbico por $100 \mathrm{~g}$ de dieta garantem maiores taxas de eclosão dos ovos e melhora o desempenho de reprodutores de tilápia mossambica. Ainda Soliman et al. (1986b) não detectaram nenhum sinal de deformidade espinal em larvas de tilápia do Nilo oriundas de ovos de peixes alimentados com dietas suplementadas com ácido ascórbico.

Halver (1985) definiu como sinais clínicos de deficiência de ácido ascórbico 
na nutrição de peixes o seguinte: lordose, escoliose, letargia, exoftalmia hemorrágica, ascite, anemia, hemorragia intramuscular e outros sintomas de escorbuto. Para Roberts \& Bullock (1989) a deficiência de ácido ascórbico em peixes é caracterizada basicamente por duas síndromes, que aparentemente se desenvolvem em todas espécies estudadas: marcada redução na capacidade de cura e a síndrome de má formação esquelética. Todas estas características aparentemente são relacionadas à redução na taxa de síntese de colágeno.

Soliman et al. (1994) verificaram ainda que tilápias do Nilo alimentadas com dietas sem ácido ascórbico exibem baixa taxa de crescimento, baixos índices de utilização de proteína líquida e de proteína digestível aparente, reduzida digestibilidade aparente da matéria seca, elevados níveis de umidade na composição da carcaça e baixos níveis de cinzas e proteína bruta na carcaça. Movimentos erráticos, desequilibrados e convulsivos, anorexia, redução do consumo, hemorragias ao redor da boca, olhos e nadadeiras, exoftalmia, e alta mortalidade foram ainda observados nos peixes alimentados com dietas sem vitamina C (Soliman et al. 1986b; Shiau \& Hsu, 1995).

Abdelghany (1996) comparando diferentes fontes de vitamina C em dietas suplementadas com 5 ou $50 \mathrm{mg} / \mathrm{kg}$ de dieta para alevinos de tilápia do Nilo, observou que os peixes alimentados com dietas livres de ácido ascórbico e/ou dietas contendo apenas 5 $\mathrm{mg} / \mathrm{kg}$ de ácido ascórbico apresentavam sinais externos de escorbuto em 10 semanas. Melhor crescimento, conversão alimentar, sobrevivência e taxa de retenção hepática de ácido ascórbico foram observados quando os peixes foram alimentados com rações contendo $50 \mathrm{mg}$ de ascorbil 2 polifosfato e ascorbil 2 sulfato/kg na dieta.

Soliman et al. (1994) sintetizaram algumas considerações para explicar o pior crescimento dos peixes alimentados com dietas sem vitamina $\mathrm{C}$ em comparação aos peixes alimentados com níveis adequados de vitamina C. Em primeiro lugar, os autores consideram que as piores taxas de crescimento observadas estão relacionadas à redução do nível de glutadiona e o aumento concomitante do nível de ácido dehidroascórbico corporal, pois a glutadiona é um promotor da divisão celular (mitose) e o ácido dehidroascórbico é um inibidor deste processo. Em adição, a deficiência do ácido 
ascórbico deprime a absorção de iodo pelos tecidos da tireóide e aumenta o nível circulatório deste mineral, o que sugere hipoatividade tireoideana. Deste modo, o retardo do crescimento pode ser devido à redução da atividade da tireóide e conseqüente redução dos níveis plasmáticos dos hormônios tireoideanos reguladores do crescimento (Matty, 1985).

A fase de larvicultura dos peixes se caracteriza pela rápida depleção das reservas de ácido ascórbico durante o desenvolvimento, e o metabolismo da larva é excepcionalmente maior nesta fase que nos estágios posteriores, sugerindo que as exigências de vitamina $\mathrm{C}$ no estágios larval e pós-larval sejam maiores. As altas taxas de inclusão desta vitamina nas dietas têm suprido as exigências dos peixes e suprimido os possíveis sintomas de deficiência. $\mathrm{O}$ estágio de desenvolvimento atual da piscicultura não permite o uso indiscriminado dos recursos disponíveis, já que os custos com arraçoamento envolvidos na produção de peixes respondem por 50 a $70 \%$ do custo operacional, o que toma proibitivo o desperdício ou uso de mega doses de qualquer ingrediente, principalmente vitaminas, que têm custo elevado. A busca de melhores índices de produtividade com níveis precisos de suplementação de vitaminas nas dietas é uma preocupação constante dos pesquisadores na área.

Em adição, a obtenção de lotes de alevinos de qualidade é fundamental para a continuidade do processo produtivo. Este aspecto do sistema de produção assume importância ainda maior no caso da tilápia do Nilo, pois a alta porcentagem de fêmeas no ambiente de criação compromete o desempenho e a qualidade final do pescado. Níveis de suplementação dietética de vitaminas que garantam uma taxa de crescimento adequada podem ser insuficientes para as reações imunológicas e respostas ao estresse ambiental. Por outro lado, a suplementação excessiva de vitaminas pode fazer com que o crescimento seja tão rápido que prejudique o índice de reversão sexual. Deste modo, devido às diversas funções e participações da vitamina $\mathrm{C}$ no metabolismo do peixe, justifica-se a investigação do efeito da suplementação de vitamina $\mathrm{C}$ na fase de reversão sexual da tilápia do Nilo. 


\section{MATERIAL E MÉTODOS}

$\mathrm{O}$ experimento avaliou a suplementação de vitamina $\mathrm{C}$ em oito níveis de inclusão, na fase de reversão sexual de tilápia do Nilo (Oreochromis niloticus). O experimento foi conduzido de janeiro a abril de 1998, no Setor de Piscicultura do Departamento de Produção Animal (LPA) da Escola Superior de Agricultura "Luiz de Queiroz" (ESALQ), "campus" Luiz de Queiroz da Universidade de São Paulo em Piracicaba, SP.

\subsection{Unidades experimentais}

Cada unidade experimental era constituída por um lote de pós-larvas de tilápia do Nilo alojadas em um "hapa" instalado dentro de uma caixa circular de fibra de vidro de 1.000L. Os hapas foram confeccionados em malhas de poliéster revestidas com cloreto de polivinila (PVC), com abertura de malha de $1,0 \mathrm{~mm}$, com dimensões de $0,40 \mathrm{x}$ $0,40 \times 0,50$ e volume de $0,08 \mathrm{~m}^{3}$ (Sansuy S.A. Indústria de Plásticos). A reversão sexual em hapas tem sido praticada com sucesso tanto em viveiros de terra como em tanques (Berger \& Rothbard, 1987; Jo et al. 1988; Popma \& Green, 1990; Phelps \& Cerezo, 1992; Vera Cruz \& Mair, 1994; Abucay \& Mair, 1997).

As caixas eram equipadas com sistemas de abastecimento e de escoamento individualizados. A água utilizada era proveniente do poço artesiano do Setor de Piscicultura do LPA e derivada de uma caixa de armazenamento de $30 \mathrm{~m}^{3}$. Cada caixa de $1.000 \mathrm{~L}$ foi estocada com 4 cascudos de tamanhos uniformes, os quais promoviam uma limpeza parcial do ambiente, alimentando-se dos resíduos e detritos das parcelas 
experimentais e evitaram o acúmulo de algas e o encrustamento de resíduos na parede, no fundo da caixa e nos hapas. Em adição, resíduos que porventura permanecessem nas caixas eram removidos por sifonamento uma vez por semana, o que reduzia a possibilidade de deterioração da qualidade da água.

Foram estocadas 600 pós-larvas/hapa, correspondendo a uma densidade de estocagem de 7.500 pós-larvas $/ \mathrm{m}^{3}$. As taxas de estocagem de pós-larvas de tilápias para procedimento de reversão sexual tanto em hapas, viveiros ou tanques pode variar de 2.000 a 6.000 pós-larvas $/ \mathrm{m}^{2}$; em sistemas de recirculação de 6.000 a 12.000 póslarvas $/ \mathrm{m}^{2}$ e em sistemas de troca contínua, de 8.000 a 17.000 pós-larvas $/ \mathrm{m}^{2}$ (Green et al. 1997). A contagem das pós-larvas foi feita por comparação visual de densidade. Três lotes de 600 pós-larvas de tilápia do Nilo foram contados e depois colocados em bacias plásticas iguais. Os lotes subsequentes foram estocados em bacias do mesmo tamanho, cor e com a mesma quantidade de água, e o número de pós-larvas de cada lote foi estimado pela observação comparativa da densidade de pós-larvas na bacia por uma única pessoa.

\subsection{Material Biológico - Pós - larvas}

As pós-larvas utilizadas foram obtidas da desova de reprodutores do Setor de Piscicultura do LPA-ESALQ, mantidos em dois hapas de reprodução com área de $12 \mathrm{~m}^{2}$, instalados em um viveiro. Estes reprodutores apresentavam as principais características morfológicas externas da espécie Oreochromis niloticus: nadadeira caudal com listras contínuas, conformação da cabeça com perfil retilíneo e cor acinzentada (Keenleyside, 1991; Popma \& Lovshin, 1994).

As larvas foram selecionadas por tamanho, conforme metodologia empregada por Popma \& Green (1990). As ninhadas dos reprodutores foram coletadas e colocadas em uma bandeja selecionadora de malha rígida de $3,2 \mathrm{~mm}$. Apenas as larvas com comprimento inferior a $13 \mathrm{~mm}$ conseguiram passar pela malha e foram utilizadas no processo de reversão sexual. O tamanho médio das larvas, no início da fase de reversão 
sexual, foi de $0,469 \pm 0,0707 \mathrm{mg}$ de peso e de 7,092 $\pm 0,58 \mathrm{~mm}$ de comprimento total.

\subsection{Tratamentos}

Os tratamentos foram definidos como os níveis de suplementação de vitamina C (ácido ascórbico cristalino com 95\% de atividade) na ração de reversão. Foram empregados oito níveis de suplementação: $0,50,100,200,400,600,800$ e $1.000 \mathrm{mg}$ de vitamina C por kg da dieta (T0; T50; T100; T200; T400; T600; T800; T1000).

\subsection{Manejo Alimentar}

A ração utilizada na fase de reversão sexual apresentava uma composição de aproximadamente $40 \%$ de proteína bruta e $3.600 \mathrm{kcal}$ de energia digestível $/ \mathrm{kg}$ de ração, tendo também suplementação mineral e vitamínica. Níveis de proteína de 25 a $50 \%$ têm sido recomendadas na fase de larvicultura (Lim, 1988; Popma \& Green, 1990). A composição da ração utilizada foi: farinha de peixe $50 \%$; farelo de soja $25 \%$; milho integral moído $21 \%$, óleo de soja $3,8 \%$, pré-mistura mineral $0,05 \%$, pré-mistura vitamínica $0,150 \%$ e vitamina $C$, suplementada nas quantidades de $0,50,100,200,400$, 600,800 e $1.000 \mathrm{mg}$ de vitamina $\mathrm{C}$ por $\mathrm{kg}$ da dieta, definindo os tratamentos do experimento.

A suplementação vitamínica das dietas foi feita nas seguintes quantidades: vitamina A 15.000.000 UI; vitamina $\mathrm{D}_{3}$ 1.500.000 UI; vitamina E $60.000 \mathrm{UI}$; vitamina $\mathrm{K}_{3}$ $3.000 \mathrm{mg}$; vitamina $B_{1}$ - tiamina $3.000 \mathrm{mg}$; vitamina $B_{2}$ - riboflavina $8.000 \mathrm{mg}$; vitamina $\mathrm{B}_{6}$ - piridoxina $4.000 \mathrm{mg}$; vitamina $\mathrm{B}_{12}$ - cianocobalina $40 \mathrm{mg}$; ácido nicotínico 40.000 $\mathrm{mg}$; ácido pantotênico $20.000 \mathrm{mg}$; ácido fólico $1.500 \mathrm{mg}$; biotina $150 \mathrm{mg}$. As dietas foram também suplementadas com minerais nas seguintes quantidades: I $1.500 \mathrm{mg}$; Co 1.000 mg; Cu 10.000 mg; Zn 100.000 mg; Fe 100.000 mg; Mn 40.000 mg.

Foi adicionado à ração de reversão, o hormônio masculino 17- $\alpha$ metiltestosterona (MT), na dose de $60 \mathrm{mg}$ de hormônio/kg de ração. O preparo da ração 
de reversão seguiu a metodologia descrita por Popma \& Green (1990), e recomendações de Botting (1991) e Hardy (1989). Os ingredientes peneirados em malha de 0,5 mm foram pesados e misturados, sem a adição da parte correspondente de vitamina C. Para adição do hormônio à mistura de ingredientes foi preparada uma solução estoque com a dissolução de $6 \mathrm{~g}$ de hormônio em $1 \mathrm{~L}$ de álcool, de modo que $10 \mathrm{ml}$ da solução estoque correspondesse a $60 \mathrm{mg}$ de hormônio. Para o preparo de $1 \mathrm{~kg}$ de ração de reversão, 10 $\mathrm{ml}$ de solução estoque foram adicionados a $490 \mathrm{ml}$ de álcool, e esta nova solução foi homogeneizada na mistura de ingredientes, e depois colocada para secagem à sombra. Depois de evaporado o álcool, foi adicionada a vitamina $\mathrm{C}$ nas doses estipuladas para cada tratamento.

As rações foram então acondicionadas em sacos plásticos de polietileno pretos e armazenadas em super-congelador. Durante o período de 30 dias de reversão, as larvas foram alimentadas 5 vezes/dia e à vontade. A duração do tratamento de reversão sexual por um período de 3 a 4 semanas pode produzir populações de tilápias compostas por mais de $95 \%$ de machos fenotípicos, entretanto, a eficiência do tratamento não pode ser afetada no prolongamento do tratamento (Tayamen \& Shelton, 1978). Dentro de cada hapa foi colocado um anel de contenção flutuante de ração, a fim de minimizar as perdas por dispersão das partículas alimentares. Os horários de alimentação foram fixados em 7:00, 9:30, 12:00, 14:30 e 17:00h.

\subsection{Coleta de Dados}

Durante toda fase de experimentação foram monitorados os seguintes parâmetros físico-químicos da água: $\mathrm{pH}$, amônia total, oxigênio dissolvido (OD) e temperatura. Os dados de temperatura e OD foram tomados diariamente pela manhã e à tarde pelo uso de um oxímetro portátil dotado de termômetro. A variação do $\mathrm{pH}$ e dos níveis de amônia total foram monitorados semanalmente no período da tarde através de um potenciômetro e um "kit" de análise de nitrogênio amoniacal, respectivamente.

Durante o período de reversão sexual, foram amostrados lotes de 20 peixes 
de cada repetição, nos dias $0,10,20$ e 30 do período, e foram determinados os parâmetros biométricos de peso e comprimento total das amostras. No final da fase de reversão sexual foram avaliadas as porcentagens de sobrevivência final de cada repetição. Finalmente, foi retirada uma amostra de 50 peixes de cada repetição, as quais foram alojadas separadamente por tratamento em oito caixas de cimento amianto de $1.000 \mathrm{~L}$, e recriadas por dois meses para verificação da porcentagem de reversão sexual por meio de seleção manual na fase juvenil. Os peixes na fase juvenil podem ser examinados individualmente através da papila uro-genital, como descrito por Obi \& Shelton (1983). A tilápia do Nilo pode ser diferenciada sexualmente com 25 a 30 gramas e a porcentagem de erro é inferior a 5\% (Poma \& Lovshin, 1994). Durante esta fase de crescimento, os peixes foram alimentados com ração comercial granulada com $32 \%$ PB e $2.800 \mathrm{kcal} / \mathrm{kg}$.

\subsection{Delineamento Experimental}

O delineamento experimental e a conseqüente análise estatística foram realizados em esquema fatorial inteiramente casualizado, para verificar a interação de peso e comprimento total entre os oito tratamentos $(0,50,100,200,400,600,800$ e $1.000 \mathrm{mg} / \mathrm{kg})$ e as quatro datas $(0,10,20$ e 30 dias $)$. Observada a significância da interação, foi feita uma decomposição dos tratamentos dentro de cada uma das datas. Os dados de peso e comprimento total final (data 30), porcentagem de sobrevivência e porcentagem de reversão sexual foram submetidos a análises de variância e ao teste de comparação de médias de Tukey. Foram então calculadas curvas de regressão não linear para sobrevivência, porcentagem de reversão sexual, peso e comprimento total final. 


\section{RESULTADOS E DISCUSSÃO}

Os parâmetros de qualidade de água monitorados durante o experimento temperatura, $\mathrm{OD}$, amônia total e $\mathrm{pH}$, mantiveram-se em níveis adequados para o conforto da espécie (Popma \& Lovshin, 1994). A temperatura média diária permaneceu acima de $25^{\circ} \mathrm{C}$; os níveis de $\mathrm{OD}$ na água foram superiores a $4,25 \mathrm{mg} / \mathrm{L}$; os valores da amônia total e do pH se mantiveram dentro dos parâmetros recomendados para criação de peixes: 0,01 mg/L para amônia e para pH valores entre 5 e 6 (Colt, 1991).

\subsection{Crescimento}

Os dados referentes aos incrementos em peso (P) e comprimento total (CT) médios estimados nas datas $0,10,20$ e 30 dias de condução do experimento estão apresentados na Tabela 1. Os dados médios estimados obtidos em cada repetição para estes fatores, e utilizados para o cálculo da média final, estão apresentados no apêndice.

Os resultados da análise de variância mostraram que houve interação significativa entre os oito tratamentos e as quatro datas, tanto para peso $(P>0,0001)$ como para comprimento total ( $\mathrm{P}>0,0001)$, como pode ser observado nas Tabelas 2 e 4 abaixo. A decomposição da interação tratamentos $\mathrm{x}$ datas indicou que havia interação significativa entre os tratamentos, nas datas 20 e 30 , para peso $(P>0,0001$ e $P>0,0001)$ e comprimento total $(\mathrm{P}>0,0001$ e $\mathrm{P}>0,0001)$, como mostrado nas Tabelas 3 e 5 abaixo. 
Tabela 1. Valores médios estimados de peso (P) e comprimento total (CT) obtidos nas biometrias realizadas durante a fase de reversão sexual da tilápia do Nilo.

\begin{tabular}{ccccccccc}
\hline \hline \multirow{2}{*}{$\begin{array}{c}\text { Tempo (dias) } \\
\text { Tratamento }\end{array}$} & \multicolumn{3}{c}{0} & \multicolumn{2}{c}{10} & \multicolumn{2}{c}{20} & \multicolumn{2}{c}{30} \\
\cline { 2 - 8 } & $\mathrm{P}(\mathrm{mg})$ & CT $(\mathrm{mm})$ & $\mathrm{P}(\mathrm{mg})$ & CT $(\mathrm{mm})$ & $\mathrm{P}(\mathrm{mg})$ & $\mathrm{CT}(\mathrm{mm})$ & $\mathrm{P}(\mathrm{mg})$ & CT (mm) \\
\hline T0 & 0,469 & 7,092 & 8,075 & 9,094 & 48,747 & 14,300 & 269,028 & 23,597 \\
T50 & 0,469 & 7,092 & 8,358 & 9,013 & 49,580 & 14,698 & 288,611 & 24,875 \\
T100 & 0,469 & 7,092 & 8,315 & 9,292 & 49,377 & 14,717 & 329,097 & 26,083 \\
T200 & 0,469 & 7,092 & 8,113 & 9,480 & 57,002 & 15,303 & 339,861 & 26,889 \\
T400 & 0,469 & 7,092 & 8,327 & 9,420 & 61,247 & 16,324 & 387,500 & 29,000 \\
T600 & 0,469 & 7,092 & 8,440 & 9,497 & 64,112 & 16,460 & 401,667 & 29,153 \\
T800 & 0,469 & 7,092 & 8,388 & 9,606 & 65,673 & 16,454 & 423,472 & 29,694 \\
T1000 & 0,469 & 7,092 & 8,508 & 9,349 & 68,170 & 16,770 & 422,361 & 29,556 \\
\hline \hline
\end{tabular}

Tabela 2. Análise da variância para a variável peso.

\begin{tabular}{cccccc}
\hline \hline Causas da & GL & Soma de & Quadrado & Valor de F & $\operatorname{Pr}>\mathrm{F}$ \\
Variação & & Quadrados & Médio & & \\
\hline Tratamento & 7 & 24024.4 & 3432.1 & 168.42 & $0.0001^{* *}$ \\
Data & 3 & 2072083.6 & 690694.5 & 33893.88 & $0.0001^{* *}$ \\
Tratamento*Data & 21 & 52603.9 & 2504.9 & 122.92 & $0.0001^{* *}$ \\
Erro & 64 & 1304.2 & 20.4 & & \\
\hline Total & 95 & 2150016.1 & & & \\
\hline \hline
\end{tabular}

** Significativo ao nível de 5\%.

\begin{tabular}{cccc}
\hline R-Quadrado & C.V. & Root MSE & Peso Médio \\
\hline 0.999393 & 4.253953 & 4.5142 & 106.12 \\
\hline
\end{tabular}


Tabela 3. Decomposição da interação tratamento $x$ data para variável peso.

\begin{tabular}{cccccc}
\hline \hline Tratamento & GL & Soma de Quadrados & Quadrado Médio & Valor de F & Pr $>\mathrm{F}$ \\
\hline 0 & 7 & $3.883917 \mathrm{E}-26$ & $5.548453 \mathrm{E}-27$ & $2.72 \mathrm{E}-28$ & 1.0000 \\
10 & 7 & 0.475982 & 0.067997 & 0.00334 & 1.0000 \\
20 & 7 & 1326.240883 & 189.462983 & 9.2974 & $0.0001^{* *}$ \\
30 & 7 & 75302 & 10757 & 527.9 & $0.0001^{* *}$ \\
\hline \hline
\end{tabular}

** Significativo ao nível de 5\%.

Tabela 4. Análise da variância para variável comprimento total.

\begin{tabular}{cccccc}
\hline \hline Causas da & GL & $\begin{array}{c}\text { Soma de } \\
\text { Quadrados }\end{array}$ & $\begin{array}{c}\text { Quadrado } \\
\text { Médio }\end{array}$ & Valor de F & Pr > F \\
Variação & 7 & 63.3264 & 9.0466 & 37.53 & $0.0001^{* *}$ \\
\hline Tratamento & 3 & 6021.1296 & 2007.0432 & 8326.79 & $0.0001^{* *}$ \\
Data & 21 & 72.8103 & 3.4672 & 14.38 & $0.0001^{* *}$ \\
Tratamento*Data & 64 & 15.4262 & 0.2410 & & \\
Erro & 95 & 6172.6925 & & & \\
\hline Total & &
\end{tabular}

** Significativo ao nível de 5\%.

\begin{tabular}{cccc}
\hline R-Quadrado & C.V. & Root MSE & Comprimento Médio \\
\hline 0.997501 & 3.316958 & 0.4910 & 14.801 \\
\hline
\end{tabular}

Tabela 5. Decomposição da interação tratamento $x$ data para variável comprimento total.

\begin{tabular}{cccccc}
\hline \hline Tratamento & GL & Soma de Quadrados & Quadrado Médio & Valor de $\mathrm{F}$ & $\operatorname{Pr}>\mathrm{F}$ \\
\hline 0 & 7 & $3.50401 \mathrm{E}-28$ & $5.005729 \mathrm{E}-29$ & $2.08 \mathrm{E}-28$ & 1.0000 \\
10 & 7 & 0.873670 & 0.124810 & 0.5178 & 0.8179 \\
20 & 7 & 20.186051 & 2.883722 & 11.9639 & $0.0001^{* *}$ \\
30 & 7 & 115.076960 & 16.439566 & 68.2042 & $0.0001^{* *}$ \\
\hline \hline
\end{tabular}

** Significativo ao nivel de $5 \%$.

A aplicação da análise de variância e do teste de comparação de médias aos dados dos oito tratamentos referentes ao peso e comprimento total na data 30 , revelaram que os tratamentos diferiram significativamente entre si, tanto em relação ao peso quanto em relação ao comprimento total. Os maiores incrementos em peso foram observados nos tratamentos T800 e T1000 e os piores resultados foram encontrados nos tratamentos T50 e T0, como pode ser observado na Tabela 6. Em relação ao incremento em comprimento, os melhores resultados foram obtidos com níveis de suplementação acima $400 \mathrm{mg}$ de 
vitamina $\mathrm{C} / \mathrm{kg}$ da dieta (T400 a T1000) e os piores para os tratamentos $\mathrm{T} 0$ e $\mathrm{T} 50$.

Tabela 6. Resultados do Teste de Tukey para comparação de médias das variáveis peso e comprimento.

\begin{tabular}{cccccccc}
\hline \hline & Peso & & & \multicolumn{3}{c}{ Comprimento } \\
\cline { 1 - 3 } \cline { 5 - 7 } Tratamento & Peso & Teste de Tukey & & Tratamento & Comprimento & Teste de Tukey \\
\hline T800 & 423.472 & A & & T800 & 29.694 & A \\
T1000 & 422.361 & AB & & T1000 & 29.556 & A \\
T600 & 401.667 & B & & T600 & 29.153 & A \\
T400 & 387.500 & C & & T400 & 29.000 & A \\
T200 & 339.861 & D & & T200 & 26.889 & B \\
T100 & 329.097 & D & & T100 & 26.083 & BC \\
T50 & 288.611 & E & & T50 & 24.875 & CD \\
T0 & 269.028 & F & T0 & 23.597 & D \\
\hline \hline
\end{tabular}

Médias com a mesma letra no Grupo de Tukey não diferem significativamente ao nível de 5\%.

Os gráficos de dispersão das médias dos tratamentos e as equações de regressão polinomial para peso e comprimento total estão apresentadas nas Figuras 1 e 2 a seguir. As derivações das equações mostraram que os níveis de inclusão que promoveram maior crescimento em peso e em comprimento foram 859,5 e 765,0 mg de vitamina $\mathrm{C} / \mathrm{kg}$ da dieta, respectivamente. 


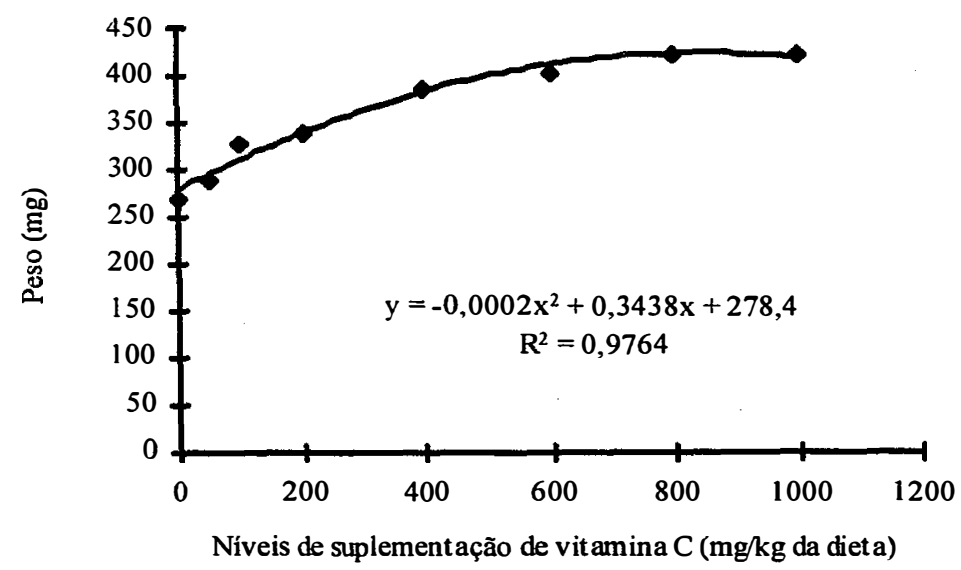

Figura 1. Gráfico de dispersão e equação de regressão polinomial para peso final, na fase de reversão sexual da tilápia do Nilo (30 dias).

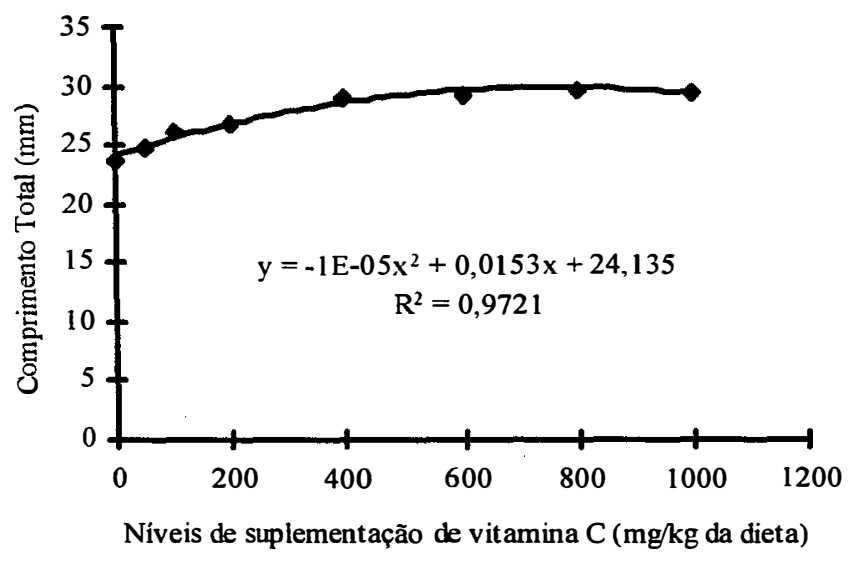

Figura 2. Gráfico de dispersão e equação de regressão polinomial para comprimento total final, na fase de reversão sexual da tilápia do Nilo (30 dias). 
As parcelas começaram a apresentar diferença significativa de crescimento, tanto em peso quanto em comprimento total após a terceira biometria, 20 dias após o início dos tratamentos. Esta situação pode ser explicada pelas observações de alguns pesquisadores que constataram a transferência de nutrientes, inclusive ácido ascórbico, dos reprodutores para larvas, via vitelo. Soliman et al. (1986b) com tilápia mossambica (Oreochromis mossambicus) e Blom \& Dabrowski (1996) com truta arco-íris (Oncorhynchus mykiss), estudaram o efeito da suplementação alimentar com ácido ascórbico na progênie e verificaram que a qualidade dos produtos obtidos era melhor para reprodutores alimentados com dietas suplementadas com vitamina C, em comparação com os reprodutores alimentados com dietas livre de vitamina $\mathrm{C}$, sugerindo a transferência de ácido ascórbico via ovo para as larvas, o que assegura alguma reserva nos estágios iniciais de vida da larva. As larvas utilizadas no experimento foram provenientes de reprodutores saudáveis, alimentados com ração completa e confinados em viveiros de terra.

A taxa de crescimento dos peixes está relacionada a diversos fatores, englobando desde o ambiente de criação, a disponibilidade de alimento $\mathrm{e}$ as características da espécie. Deste modo, os índices de crescimento das pós-larvas de tilápias ao final do período de reversão sexual podem variar muito. De acordo com Popma \& Green (1990) e Popma \& Lovshin (1994), ao final do período de reversão sexual o peso médio dos peixes poderá ser de 100 a $500 \mathrm{mg}$, e a temperatura da água e a qualidade da ração são os fatores que mais influenciam esta variação.

Vera Cruz \& Mair (1994) observaram que o ganho de peso médio de tilápias ao final do período de reversão sexual realizada em hapas pode variar de 221,4 a 419,0 mg. Ainda Vera Cruz \& Mair (1994) avaliando a influência da densidade de estocagem no ganho de peso de tilápias ao final do período de reversão sexual, verificaram que o ganho de peso apresentou índices de 33,5, 56,2 e 145,6 mg, respectivamente, para densidades de estocagem de 10.000; 6.000 e 2.000 pós-larvas $/ \mathrm{m}^{3}$. A deterioração dos parâmetros de qualidade de água causada por altas densidades de estocagem na fase de reversão sexual pode interferir negativamente no crescimento dos peixes, tomando-se o 
principal fator de variação no ganho de peso das pós-larvas neste período (Varadaraj et al. 1994; Phelps et al. 1995).

Outros autores têm conseguido índices de crescimento superiores à faixa encontrada por Popma \& Lovshin (1994). É o caso de Varadaraj \& Pandian (1991), que obtiveram índices médios de crescimento maiores que $540 \mathrm{mg}$, com um máximo de 1.083 $\mathrm{mg}$, e Phelps et al. (1995), que conseguiram um ganho de peso variando de 760 a 2.800 $\mathrm{mg}$, trabalhando com diferentes densidades de estocagem em viveiros de terra.

Diversos outros pesquisadores têm relatado os efeitos da falta ou da utilização de níveis inadequados de ácido ascórbico na dieta em diversas espécies. Soliman et al. (1986b) observaram que larvas de tilápia mossambica alimentadas com dietas desprovidas de ácido ascórbico apresentam baixa taxa de crescimento específico, piores índices de conversão alimentar e taxa de eficiência protéica, e menor taxa de sobrevivência. Estes mesmos autores atribuíram a severa redução no crescimento e o pior índice de conversão alimentar obtidos das larvas alimentadas com dietas sem ácido ascórbico à anorexia e redução da atividade voluntária dos peixes - letargia.

Mahajan \& Agrawal (1980a) trabalhando com larvas de carpa indiana submetidas a diferentes níveis de inclusão de vitamina $\mathrm{C}$ na dieta, observaram que as taxas de crescimento das larvas aumentaram proporcionalmente ao aumento da quantidade de ácido ascórbico na dieta, até um máximo de $600 \mathrm{mg} / \mathrm{kg}$. Os piores índices de crescimento das larvas foram observados nos grupos que receberam uma dieta sem suplementação de vitamina $\mathrm{C}$, ou cuja dieta foi suplementada com $60 \mathrm{mg}$ de vitamina $\mathrm{C}$ por kg da dieta.

Neste trabalho, os melhores índices de ganho de peso foram observados em níveis de suplementação acima de $800 \mathrm{mg}$ de vitamina $\mathrm{C} / \mathrm{kg}$ da dieta, e os melhores índices de incremento em comprimento foram observados para níveis de suplementação de vitamina C acima de $400 / \mathrm{kg}$ da dieta. A equação de regressão polinomial dos dados apresentou valores para ótimo desempenho de 859,5 e 765,0 $\mathrm{mg}$ de vitamina $\mathrm{C} / \mathrm{kg}$ da dieta, respectivamente para ganho de peso e incremento em comprimento (Figuras 1 e 2). Os alevinos obtidos ao final do nosso experimento estavam na faixa de peso e 
comprimento adequados para comercialização e dentro dos padrões normais de crescimento. O peso e o comprimento total variaram de 269,028 a 423,472 mg e de 23,597 a 29,694 mm, respectivamente. Estes resultados comprovam que o aumento dos níveis de suplementação com vitamina $\mathrm{C}$ na dieta proporciona melhores índices de desempenho.

\subsection{Sobrevivência e Reversão Sexual}

$\mathrm{Na}$ Tabela 7 estão apresentadas as porcentagens médias estimadas de sobrevivência (S\%) obtidas no final da fase de reversão sexual e as porcentagens médias de reversão sexual (RS\%) obtidas através da seleção manual na fase juvenil. Os valores médios estimados da porcentagem de sobrevivência de cada repetição estão apresentados no apêndice.

Tabela 7. Porcentagem média estimada de sobrevivência (S\%) e porcentagem média de reversão sexual (RS\%) por tratamento ao final da fase de reversão sexual de tilápia do Nilo.

\begin{tabular}{ccc}
\hline \hline Tratamentos & S\% & RS\% \\
\hline T0 & 26,556 & 91 \\
T50 & 37,889 & 89 \\
T100 & 44,111 & 90 \\
T200 & 61,722 & 89 \\
T400 & 63,111 & 91 \\
T600 & 61,778 & 89 \\
T800 & 61,611 & 91 \\
T1000 & 67,889 & 90 \\
\hline \hline
\end{tabular}

A análise de variância dos dados de S\% em função da variação do nível de suplementação de vitamina $\mathrm{C}$ nas dietas indicou que houve diferença significativa entre os tratamentos $(\mathrm{P}>0,001)$. A aplicação do teste de comparação de médias comprova a 
diferença significativa entre os tratamentos, como demonstrado na Tabela 8.

Entretanto, a aplicação da análise de variância e do teste de comparação de médias sobre os dados de RS\% revelou não existir diferenças estatisticamente significativas entre os tratamentos $(P>0,9993)$ em relação aos valores observados de porcentagem de machos nas populações resultante do procedimento de reversão. As porcentagens de machos nas populações dos diferentes tratamentos variou de 89 a $91 \%$ (Tabelas 9 e 10).

Tabela 8. Resultados da análise da variância para variável reversão sexual.

\begin{tabular}{cccccc}
\hline $\begin{array}{c}\text { Causa da } \\
\text { Variação }\end{array}$ & GL & $\begin{array}{c}\text { Soma de } \\
\text { Quadrados }\end{array}$ & $\begin{array}{c}\text { Quadrado } \\
\text { Médio }\end{array}$ & Valor de F & Pr $>$ F \\
\hline Tratamento & 7 & 0.00198333 & 0.00028333 & 0.07 & 0.9993 \\
Erro & 16 & 0.06720000 & 0.00420000 & & \\
Total & 23 & 0.06918333 & & & \\
\hline \hline
\end{tabular}

\begin{tabular}{cccc}
\hline R-Sguare & C.V. & Root MSE & RS Mean \\
\hline 0.028668 & 7.194162 & 0.064807 & 0.90083333 \\
\hline
\end{tabular}

Tabela 9. Resultados da análise da variância para variável sobrevivência.

\begin{tabular}{cccccc}
\hline \hline Causa da & GL & $\begin{array}{c}\text { Soma de } \\
\text { Quadrados }\end{array}$ & $\begin{array}{c}\text { Quadrado } \\
\text { Médio }\end{array}$ & Valor de F & Pr $>\mathrm{F}$ \\
Variação & 7 & 4673.473204 & 667.639029 & 57.01 & $0.0001^{* *}$ \\
\hline Tratamento & 16 & 187.374519 & 11.710907 & & \\
Erro & 23 & 4860.847724 & & & \\
Total & & & & \\
\hline \hline
\end{tabular}

** Significativo ao nível de 5\%.

\begin{tabular}{cccc}
\hline R-Square & C.V. & Root MSE & SOB Mean \\
\hline 0.961452 & 6.446689 & 3.422120 & 53.0833750 \\
\hline
\end{tabular}


Tabela 10. Resultados do Teste de Tukey para comparação de médias das variáveis reversão sexual e sobrevivência.

\begin{tabular}{|c|c|c|c|c|c|}
\hline \multicolumn{3}{|c|}{ Reversão Sexual } & \multicolumn{3}{|c|}{ Sobrevivência } \\
\hline Tratamento & Média & Teste de Tukey & Tratamento & Média & Teste de Tukey \\
\hline T0 & 0.9133 & A & $\mathrm{T} 1000$ & 67.889 & A \\
\hline $\mathrm{T} 800$ & 0.9133 & A & $\mathrm{T} 400$ & 63.111 & A \\
\hline $\mathrm{T} 400$ & 0.9067 & A & T600 & 61.778 & A \\
\hline $\mathrm{T} 100$ & 0.9000 & A & $\mathrm{T} 200$ & 61.722 & A \\
\hline T1000 & 0.9000 & A & $\mathrm{T} 800$ & 61.611 & A \\
\hline T600 & 0.8933 & A & $\mathrm{T} 100$ & 44.111 & B \\
\hline $\mathrm{T} 200$ & 0.8933 & A & $\mathrm{T} 50$ & 37.889 & B \\
\hline $\mathrm{T} 50$ & 0.8867 & A & T0 & 26.555 & $\mathrm{C}$ \\
\hline
\end{tabular}

Médias com a mesma letra no Grupo de Tukey não diferem significativamente ao nível de 5\%.

$\mathrm{O}$ aumento da suplementação de vitamina $\mathrm{C}$ na dieta proporcionou maiores porcentagens de sobrevivência média no final do tratamento. Os tratamentos T200 a T1000 apresentaram as maiores porcentagens de sobrevivência final, com valores acima de $61,61 \%$, e não apresentaram diferenças estatisticamente significativas. Já os tratamentos T50 e T100 apresentaram sobrevivência média final de 37,88\% e 44,11\%, respectivamente, e o pior resultado foi observado para o tratamento T0, com $26,55 \%$ de sobrevivência média final.

O gráfico de dispersão das médias dos tratamentos e a equação de regressão polinomial para sobrevivência está apresentada na Figura 3 abaixo e a derivação da sua equação mostrou que o nível de inclusão que promoveu maior sobrevivência final foi $685,7 \mathrm{mg}$ de vitamina $\mathrm{C} / \mathrm{kg}$ da dieta. 


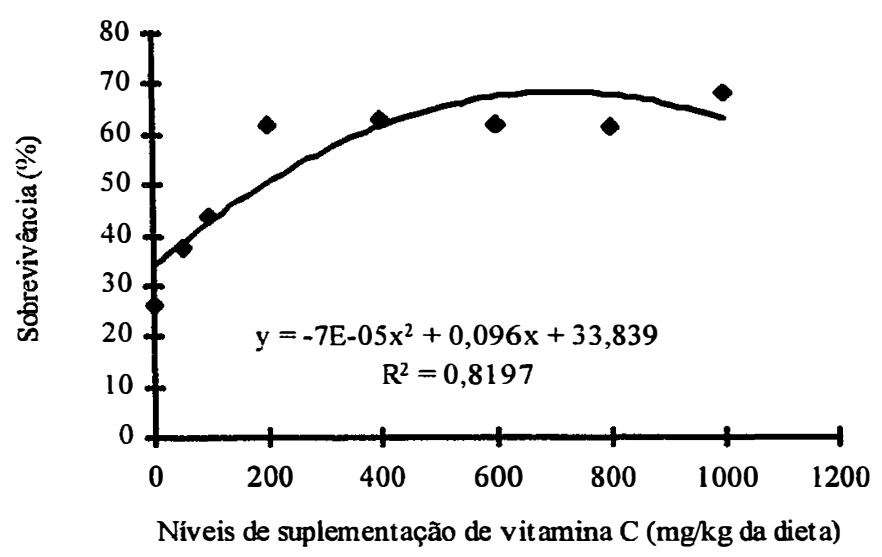

Figura 3. Gráfico de dispersão e equação de regressão polinomial para sobrevivência final, na fase de reversão sexual da tilápia do Nilo (30 dias).

Os valores de sobrevivência final no processo de reversão sexual com tilápias podem variar muito em função de diversos fatores. Popma \& Lovshin (1994) citam que a sobrevivência final encontrada nestes tratamentos de reversão sexual pode ser menor que $50 \%$, mas normalmente está entre 70 e $\mathbf{8 0 \%}$. Tais valores puderam ser confirmados por Varadaraj \& Pandian (1991), que relataram 74 a 98\% de sobrevivência; Vera Cruz \& Mair (1994) encontraram valores de 70,8 à 84,7\% em hapas; e Abucay \& Mair (1997) obtiveram sobrevivência final de 68,0 a $99,3 \%$ com tilápias do Nilo submetidas ao tratamento de reversão sexual em hapas, a uma densidade de estocagem de 1.800 póslarvas $/ \mathrm{m}^{3}$, entre outros autores.

A densidade de estocagem é um importante fator relacionado com a sobrevivência. Vera Cruz \& Mair (1994) constataram que o aumento da densidade de estocagem reduz a sobrevivência final de pós-larvas de tilápias submetidas à reversão sexual em hapas, e relataram valores de 92,$2 ; 76,1$ e $68,9 \%$ de sobrevivência para densidades de estocagem de $2.000 ; 6.000$ e 10.000 pós-larvas $/ \mathrm{m}^{3}$, respectivamente. Resultados semelhantes foram obtidos no trabalho de Varadaraj et al. (1994), que afirmaram que a sobrevivência foi drasticamente diminuída quando a densidade de 
estocagem foi maior que 500 pós-larvas $/ \mathrm{m}^{2}$. À luz dos resultados relatados acima, podemos inferir que os valores de $\mathrm{S} \%$ obtidos neste experimento estão dentro da normalidade, em função da densidade de estocagem utilizada no trabalho.

Níveis inadequados de vitamina $\mathrm{C}$ na dieta aumentam a mortandade de peixes nas fases larval e pós-larval, em que apresentam ritmo de desenvolvimento mais acentuado. É muito difícil a observação dos sintomas de deficiência nutricional em larvas e pós-larvas alimentadas com dietas onde os níveis de vitamina $\mathrm{C}$ estão abaixo das exigências nutricionais, principalmente em situações em que a disponibilidade do alimento natural é reduzida, e o sintoma mais aparente é a mortalidade. Para Fracalossi (1998) os níveis de nutrientes que podem promover um rápido crescimento não são necessariamente aqueles que induziriam resistência a doenças ou um fortalecimento do sistema imunológico. Os peixes podem estar deficientes em algum nutriente, sem exibir sinais clínicos de deficiência nutricional.

Soliman et al. (1994) observaram que a sobrevivência de alevinos de tilápia do Nilo é reduzida de 80 para $50 \%$ quando as dietas não são suplementadas com ácido ascórbico. Estes pesquisadores afimaram que a mortandade observada nas populações de peixes com privação de vitamina $\mathrm{C}$ na dieta é, certamente, um resultado do efeito cumulativo da deficiência crônica deste nutriente em todos os processos metabólicos em que ele é essencial. Mahajan \& Agrawal (1980a) também verificaram índices de mortandade de $42 \%$ e $38 \%$, respectivamente, em populações de larvas de carpa indiana (Cirrhina mrigala) alimentadas com dietas sem suplementação de ácido ascórbico ou com suplementação de $60 \mathrm{mg}$ de vitamina C por kg de alimento. Shiau \& Jan (1992) também verificaram que a deficiência de ácido ascórbico na dieta de juvenis de tilápias resulta na mortandade de $37,78 \%$ da população.

Neste experimento, a sobrevivência foi significativamente maior para os tratamentos com suplementação de vitamina $\mathrm{C}$ acima de $200 \mathrm{mg} / \mathrm{kg}$ - sobrevivências médias estimadas de $61,61 \%$ à $67,89 \%$, enquanto que os níveis de suplementação de 50 e $100 \mathrm{mg} / \mathrm{kg}$ apresentaram índices de sobrevivência de 37,89\% e 44,11\%, respectivamente. E finalmente, o tratamento com o menor nível de suplementação teve o pior desempenho 
em relação ao índice de sobrevivência, que foi de apenas $26,55 \%$.

Preconiza-se que o índice de sucesso na reversão sexual de tilápia do Nilo porcentagem de machos encontrada nas populações submetidas ao processo - seja superior a 95\%, mas usualmente encontra-se entre 80 e 90\% (Popma \& Lovshin, 1994). Green et al. (1997) fizeram uma revisão sobre o tema e concluíram que a administração oral de 30 a $60 \mathrm{mg}$ de metiltestosterona por $\mathrm{kg}$ de ração para larvas de tilápia durante um período de 3 a 4 semanas produz populações compostas por mais de $95 \%$ de machos.

Vários autores, como Phelps et al. (1995) e Vera Cruz \& Mair (1994) relatam porcentagens de reversão sexual variando de 85 a $98,2 \%$, e creditam esta variação a condições de condução do processo de reversão: uso de tanques, viveiros ou hapas; variação na densidade de estocagem; etc. Já para Varadaraj et al. (1994) o sucesso do processo de reversão sexual e a taxa de crescimento das pós-larvas dependem diretamente da taxa diária de alimentação, que deve ser fixada em $25 \%$ do peso vivo, e não da densidade de estocagem.

Neste experimento, não foram observadas diferenças estatisticamente significativas entre os tratamentos em relação ao índice de sucesso na reversão sexual. A porcentagem média de machos encontrada variou de 89 a $91 \%$. Os resultados obtidos na equação de regressão polinomial indicam que o valor da suplementação para otimização do ganho de peso seria de $859,5 \mathrm{mg} / \mathrm{kg}$ e para otimização do incremento em comprimento seria de $765 \mathrm{mg} / \mathrm{kg}$. Em relação à otimização da $\mathrm{S \%}$, a equação de regressão polinomial indica que a suplementação de vitamina $\mathrm{C}$ deve ser feita na dose de $685,7 \mathrm{mg} / \mathrm{kg}$. Portanto, uma suplementação de ácido ascórbico nas dietas de pós larvas de tilápia do Nilo na faixa de 765 a $859,5 \mathrm{mg} / \mathrm{kg}$ seria desejável para otimizar a taxa de crescimento e a sobrevivência final.

As altas doses de suplementação, indicadas como resultados das equações de regressão polinomial do experimento para ótimo desempenho, são um reflexo do tipo e da composição da dieta utilizada. A ração em pó utilizada na alimentação inicial de peixes sofre perdas com lixiviação e solubilização dos nutrientes na água em função da desagregação das partículas alimentares, exigindo níveis mais elevados de suplementação. 
O ácido ascórbico é um dos nutrientes cuja estabilidade é mais comprometida, sujeito a grandes perdas no processo de alimentação de peixes com rações pulverizadas (Halver, 1989; Steffens, 1989; Tacon, 1991). Para reduzir a possibilidade de ocorrência de problemas com deficiência de vitamina $\mathrm{C}$ na dieta, é recomendada a utilização de suplementação excessiva na dieta, ou a utilização de formas mais estáveis ou protegidas de ácido ascórbico, menos sujeitas a perdas por oxidação ou lixiviação (Soliman et al. 1986a; Tacon, 1991; Soliman et al. 1994; Shiau \& Hsu, 1995; Abdelghany, 1996; Nitzan et al. 1996). 


\section{CONCLUSÕES}

Com base na discussão dos resultados, pode-se inferir que não há efeito direto da suplementação da dieta com ácido ascórbico no índice de sucesso na reversão sexual da tilápia do Nilo. Os resultados obtidos permitem ainda concluir que o ganho de peso e o incremento em comprimento total de pós-larvas de tilápia do Nilo são otimizados, respectivamente, com níveis de inclusão entre 765 a $859,5 \mathrm{mg}$ de ácido ascórbico/kg da dieta, e que níveis de suplementação de $685,7 \mathrm{mg} / \mathrm{kg}$ permitem obter melhores índices de sobrevivência de larvas de tilápia do Nilo submetidas a tratamento hormonal para reversão sexual. 


\section{REFERÊNCIAS BIBLIOGRÁFICAS}

ABDELGHANY, A. E. Growth response of Nile tilapia Oreochromis niloticus to dietary L-ascorbic acid, L-ascorbyl-2-sulfate, and L-ascorbyl-2-polyphosphate. Journal of the World Aquaculture Society, v. 27, p. 449 - 455, 1996.

ABUCAY, J.S.; MAIR, G.C. Hormonal sex reversal of tilapias: implications of hormone treatment application in closed water systems. Aquaculture Research, v. 28, p. 841- 845, 1997.

BARDACH, J.E.; RYTHER, J.H. ; MCLARNEY, W.O. Aquaculture: the farming and husbandry of freshwater and marine organisms. New York: Science Editions, 1972. $868 \mathrm{p}$.

BERGER, A.; ROTHBARD, S. Androgen induced sex-reversal of red tilapia fry stocked in cages within ponds. Bamidgeh, v. 39, p. 49 - 57, 1987.

BLOM, J.H; DABROWSKI, K. Ascorbic acid metabolism in fish: is there a maternal effect on the progeny? Aquaculture, v. 147, p. 215 - 224, 1996.

BOTTING, C.C. Extrusion technology in aquaculture feed processing. In: AQUACULTURES FEED PROCESSING AND NUTRITION WORKSHOP, Singapore, 1991. Proceedings. Singapore: American Soybean Association, 1991. p.129 - 137.

BOWEN, S.H. Feeding digestion and growth - qualitative considerations. In: CONFERENCE INTERNATIONAL CENTER OF LIVING AQUATIC RESOURCES MANAGEMENT 7., Manila, 1982. The biology and culture of tilapias: proceedings. Manila: ICLARM, 1982. p. 141 - 156. 
COLT, J. Aquacultural production systems. Journal of Animal Science, v. 69, p. 4183-4192, 1991.

FRACALOSSI, D.M. Doenças nutricionais em peixes. In: SIMPÓSIO SOBRE MANEJO E NUTRIÇÃO DE PEIXES, 2., Piracicaba, 1998. Ana is. Campinas: CBNA, 1998. p. 97 - 122.

GREEN, B.W.; VEVERICA, K.L.; FITZPATRICK, M.S. Fry and fingerling production. In: EGNA, H.S.; BOYD, C.E. (Ed.) Dynamics of pond aquaculture. Boca Raton: CRC Press, 1997. p. 215 - 243.

HALVER, J.E. Recent advances in vitamin nutrition and metabolism in fish. In:COWEY, C.B; MACKIE, A.M.; BELL, J.G. (Ed.) Nutrition and feeding in fish. London: Academic Press, 1985. p. 415 - 429.

HALVER, J.E. The vitamins. In: HALVER, J.E. (Ed.) Fish nutrition. Washington: Academic Press, 1989. p. 31 - 109.

HARDY, R.W. Diet preparation. In: HALVER, J.E. (Ed.) Fish nutrition. Washington: Academic Press, 1989. p. 476 - 549.

HEPHER, B.; PRUGININ, Y. Commercial fish farming. New York: John Willey, $1981.261 \mathrm{p}$.

JALABERT, B.; ZOHAR, Y. Reproductive physiology in cichid fishes, with particular reference to Tilapia and Sarotherodon. In: CONFERENCE INTERNATIONAL CENTER OF LIVING AQUATIC RESOURCES MANAGEMENT 7., Manila, 1982. The biology and culture of tilapias: proceedings. Manila: ICLARM, 1982. p. $129-140$.

JO, J.-Y.; SMITHERMAN, R.O.; BEHRENDS,L.L. Effects of dietary $17 \boldsymbol{\alpha}$ methyltestosterone on sex reversal and growth of Oreochromis aureus. In: INTERNATIONAL SYMPOSIUM ON TILAPIA IN AQUACULTURE, 2., Bangkok, 1987. Manila: ICLARM, 1988. p. 203 - 207. 
KEENLEYSIDE, M.H.A. Cichlidae fishes: Behaviour, ecology and evolution. London: Chapman \& Hall, 1991. 378 p.

LAGLER, K.F.; BARDACH, J.E.; MILLER, R.R.; PASSINO, D.R.M. Ichthyology. 2.ed. New York: Jonh Wiley, 1977. 506 p.

LAHAV, M.; LAHAV, E. The developmentof all-male tilapia hybrids in Nir David. Bamidgeh, v. 42, p. 58 - 61, 1990.

LIM, C. Pratical feeding: tilapias. In: LOVELL, T. (Ed.) Nutrition and feeding of fish. New York: Van Nostrand Reinhold, 1988. p. $163-182$.

LITTLE, D.C.; MACINTOSH, D.J.; EDWARDS, P. Improving spawning synchrony in the Nile tilapia , Oreochromis niloticus (L.). Aquaculture Fisheries Management, v. 24, p. 399 - 405, 1993.

LOVELL, R.T. Nutrition and feeding. In: BROWN, E.E.; GRATZEK, J.B. Fish farming book. Westport: Avi Publish Company, 1980. p. 207 - 236.

LOVELL, R.T. Nutrition and feeding of fish. New York: Van Nostrand Reinhold, 1989. $260 \mathrm{p}$.

MAHAJAN, C.L.; AGRAWAL, N.K. Nutritional requirement of ascorbic acid by indian major carp, Cirrhina mrigala, during early growth. Aquaculture, v. 19, p. 37 - 48, 1980a.

MAHAJAN, C.L.; AGRAWAL, N.K. The role of vitamin C in calcium uptake by fish. Aquaculture, v. 19, p. 287 - 294, 1980 b.

MATTY, A.J. Fish endocrinology. Portland: Timber Press, 1985. 267 p.

MEADE, J.W. Aquaculture management. New York: Chapman \& Hall, 1989. 175 p.

NATIONAL RESEARCH COUNCIL. Nutrient requirement of warmwater fishes and shellfishes. Washigton: National Academic Press, 1983. 102 p.

NATIONAL RESEARCH COUNCIL. Nutrient requirement of fishe. Washigton: 
National Academic Press, 1993. 115 p.

NITZAN, S.; ANGEONI, H.; GUR, N. Effects of ascorbic acid polyphosphate (AAPP) enrichment on growth, survival and disease resistance of hybrid tilapia. The Israeli Journal of Aquaculture - Bamidgeh, v. 48, p. 133 - 141, 1996.

OBI, A.; SHELTON, W.L. Androgen and estrogen sex-reversal in Tilapia hornorun. In: INTERNATIONAL SYMPOSIUM ON TILAPIA IN AQUACULTURE, Nazareth, 1983. Proceedings. Tel Aviv: Tel Aviv University, 1983. p. 165 -183.

PANDIAN, T.J.; SHEELA, S.G. Hormonal induction of sex reversal in fish. Aquaculture, v. 138, p. 1 - 22, 1995.

PHELPS, R.P.; CEREZO, G. The effect of confinement in hapas on sex reversal and growth of Oreochromis niloticus. Journal of Applied Aquaculture, v. 1, p. 73-81, 1992.

PHELPS, R.P.; SALAZAR, G.C.; ABE, V.; ARGUE, B.J. Sex reversal and nursery growth of Nile tilapia, Oreochromis niloticus (L.), free-swimming in earthen ponds. Aquaculture Research, v. 26, p. 293 - 295, 1995.

PHILIPPART, J-CL.; RUWET, J-CL. Ecology and distribuition of tilapias. In: CONFERENCE INTERNATIONAL CENTER OF LIVING AQUATIC RESOURCES MANAGEMENT 7., Manila, 1982. The biology and culture of tilapias: proceedings. Manila: ICLARM, 1982. p. 15 -59.

POPMA, T.J.; GREEN, B.W. Aquacultural production manual: sex reversal of tilapia in earthen ponds. Auburn: Auburn University, International Center for Aquaculture, 1990. 15 p. (Research and Development Series, 35).

POPMA, T.J.; LOVSHIN, L.L. Worldwide prospects for commercial production of tilapia. Auburn: Aubum University, Center for Aquaculture and Aquatic Enviroments, Department of Fisheries and Allied Aquacultures, 1994. 40 p.

PRUGININ, Y.; ROTHBARD, S.; WOHLFARTH, G.; HALEVY, A.; MOAV, R.; 
HULATA, G. All-male broods of Tilapia nilotica x T. aurea hybrids. Aquaculture, v. 6 , p. $11-21,1975$.

PULLIN, R.S.V. Cichlids in aquaculture. In KEENLEYSIDE, M.H.A. (Ed.) Cichlids fishes: Behaviour, ecology and evolution. London: Chapman \& Hall, 1991. p. 280-309.

ROBERTS, R.J.; BULLOCK, A.M. Nutritional pathology. In: HALVER, J.E. (Ed.) Fish nutrition. Washington: Academic Press, 1989. p. 423 - 473.

SANTIAGO, C.B.; REYES, O.S. Effects of dietary source on reproductive performance and tissue levels of Nile tilapia Oreochromis niloticus (Linnaeus) broodstock. Journal of Applied Ichthyology, v. 9, p. 33 - 40, 1993.

SCOTT, A.G.; PENMAN, D.J.; BEARDMORE, J.A.; SKIBINSKI, D.O.F. The "YY" supermale in Oreochromis niloticus (L.) and its potential in aquaculture. Aquaculture, v. 78, p. 237 - 251, 1989.

SHIAU, S.-Y.; HSU, T.-S. L- Ascorbyl-2-sulfate has equal antiscorbutic activity as Lascorbyl-2-monophosphate for tilapia, Oreochromis niloticus $\mathrm{x} O$. aureus. Aquaculture, v. 133, p. 147 - 157, 1995.

SHIAU, S.-Y.; JAN, F.L. Dietary ascorbic acid requirement of juvenile tilapia Oreochromis niloticus X O. aureus. Nippon Suisan Gakkaishi Bulletin of the Japanese Society of Scientific Fisheries, v. 58, p. 671 - 675, 1992. Abstract.

SOLIMAN, A.K.; JAUNCEY, K.; ROBERTS, R.J. The effect of varying forms of dietary ascorbic acid on the nutrition of juvenile tilapias (Oreochromis niloticus). Aquaculture, v. 52, p. 1 - 10, 1986a.

SOLIMAN, A.K.; JAUNCEY, K.; ROBERTS, R.J. The effect of dietary ascorbic acid supplementation on hatchability, survival rate and fry performance in Oreochromis mossambicus (Peters). Aquaculture, v. 59, p. 197 - 208, 1986b.

SOLIMAN, A.K.; JAUNCEY, K.; ROBERTS, R.J. Water-soluble vitamin requirements 
of tilapia: ascorbic acid (vitamin C) requirement of Nile tilapia, Oreochromis niloticus (L.). Aquaculture and Fisheries Management, v. 25, p. 269 - 278, 1994.

STEFFENS, W. Principles of fish nutrition. Chichester: Ellis Horwood, 1989. 384 p.

TACON, A.G.J. Vitamin nutrition in shrimp and fsh. In: AQUACULTURES FEED PROCESSING AND NUTRITION WORKSHOP, Singapore, 1991. Proceedings. Singapore: American Soybean Association, 1991.p. 10 - 41.

TAYAMEN, M.M.; SHELTON, W.L. Inducement of sex reversal in Sarotherodon niloticus (Linnaeus). Aquaculture, v. 14, p. 349 - 354, 1978.

TREWAVAS, E. Tilapias: taxonomy and speciation. In: CONFERENCE INTERNATIONAL CENTER OF LIVING AQUATIC RESOURCES MANAGEMENT 7., Manila, 1982. The biology and culture of tilapias: proceedings. Manila: ICLARM, 1982. p. 3 - 13.

VARADARAJ, K.; PANDIAN, T.J. Effect of solubilizing $17 \alpha$-ethynyltestosterona in three different solvents on sex reversal of Mozambique tilapia. The Progressive Fish-Culturist, v. 53, p. 67 - 71, 1991.

VARADARAJ, K.; KUMARI, S.S.; PANDIAN, T.J. Comparison of conditions for hormonal sex reversal of Mozambique tilapias. The Progressive Fish-Culturist, v.56, p. $81-90,1994$.

VERA CRUZ, E.M.; MAIR, G.C. Conditions for effective androgen sex reversal in Oreochromis niloticus (L.). Aquaculture, v. 122, p. 237 - 248, 1994.

WOHLFARTH, G.W. The unexploited potential of tilapia hybrids in aquaculture. Aquaculture and Fisheries Management, v. 25, p. 781 - 788, 1994. 


\section{APÊNDICE}


Peso médio em cada repetição, em cada biometria

\begin{tabular}{lccccc}
\hline Tratamento & Cx & Peso 0 & Peso 10 & Peso 20 & Peso 30 \\
\hline T0-1 & 1 & 0.469 & 8.695 & 44.655 & 275.417 \\
T0-2 & 9 & 0.469 & 7.990 & 50.250 & 265.833 \\
T0-3 & 17 & 0.469 & 7.540 & 51.335 & 265.833 \\
T50-1 & 2 & 0.469 & 9.225 & 48.540 & 299.167 \\
T50-2 & 10 & 0.469 & 7.795 & 51.595 & 280.417 \\
T50-3 & 18 & 0.469 & 8.055 & 48.605 & 286.250 \\
T100-1 & 3 & 0.469 & 8.150 & 48.470 & 340.833 \\
T100-2 & 11 & 0.469 & 8.405 & 48.200 & 320.000 \\
T100-3 & 19 & 0.469 & 8.390 & 51.460 & 326.458 \\
T200-1 & 4 & 0.469 & 8.055 & 55.320 & 332.500 \\
T200-2 & 12 & 0.469 & 8.520 & 63.125 & 339.167 \\
T200-3 & 20 & 0.469 & 7.765 & 52.560 & 347.917 \\
T400-1 & 5 & 0.469 & 8.235 & 60.695 & 379.583 \\
T400-2 & 13 & 0.469 & 8.430 & 59.505 & 396.250 \\
T400-3 & 21 & 0.469 & 8.315 & 63.540 & 386.667 \\
T600-1 & 6 & 0.469 & 8.695 & 63.915 & 401.250 \\
T600-2 & 14 & 0.469 & 8.455 & 62.065 & 391.250 \\
T600-3 & 22 & 0.469 & 8.170 & 66.355 & 412.500 \\
T800-1 & 7 & 0.469 & 8.365 & 71.120 & 421.667 \\
T800-2 & 15 & 0.469 & 8.335 & 58.710 & 430.000 \\
T800-3 & 23 & 0.469 & 8.465 & 67.190 & 418.750 \\
T1000-1 & 8 & 0.469 & 8.465 & 71.150 & 421.667 \\
T1000-2 & 16 & 0.469 & 8.595 & 67.480 & 417.083 \\
T1000-3 & 24 & 0.469 & 8.465 & 65.880 & 428.333 \\
\hline
\end{tabular}

Comprimento médio em cada repetição, em cada biometria

\begin{tabular}{lccccc}
\hline Tratamento & Cx & Comp 0 & Comp 10 & Comp 20 & Comp 30 \\
\hline T0-1 & 1 & 6.877 & 9.485 & 13.623 & 23.875 \\
T0-2 & 9 & 6.877 & 9.043 & 14.390 & 23.167 \\
T0-3 & 17 & 6.877 & 8.755 & 14.888 & 23.750 \\
T50-1 & 2 & 6.877 & 8.975 & 14.440 & 25.042 \\
T50-2 & 10 & 6.877 & 8.958 & 15.260 & 24.958 \\
T50-3 & 18 & 6.877 & 9.105 & 14.393 & 24.625 \\
T100-1 & 3 & 6.877 & 9.090 & 14.555 & 26.750 \\
T100-2 & 11 & 6.877 & 9.343 & 14.440 & 24.958 \\
T100-3 & 19 & 6.877 & 9.443 & 15.155 & 26.542 \\
T200-1 & 4 & 6.877 & 9.535 & 14.700 & 26.542 \\
T200-2 & 12 & 6.877 & 9.455 & 16.323 & 26.458 \\
T200-3 & 20 & 6.877 & 9.450 & 14.885 & 27.667 \\
T400-1 & 5 & 6.877 & 9.238 & 16.525 & 27.833 \\
T400-2 & 13 & 6.877 & 9.575 & 16.750 & 30.000 \\
T400-3 & 21 & 6.877 & 9.448 & 15.698 & 29.167 \\
T600-1 & 6 & 6.877 & 9.713 & 16.375 & 28.792 \\
T600-2 & 14 & 6.877 & 9.540 & 16.075 & 28.750 \\
T600-3 & 22 & 6.877 & 9.238 & 16.930 & 29.917 \\
T800-1 & 7 & 6.877 & 9.640 & 16.490 & 28.917 \\
T800-2 & 15 & 6.877 & 9.428 & 17.350 & 30.583 \\
T800-3 & 23 & 6.877 & 9.750 & 15.523 & 29.583 \\
T1000-1 & 8 & 6.877 & 9.198 & 16.925 & 28.750 \\
T1000-2 & 16 & 6.877 & 9.435 & 16.735 & 29.750 \\
T1000-3 & 24 & 6.877 & 9.415 & 16.650 & 30.167 \\
\hline
\end{tabular}


Sobrevivência média estimada e porcentagem de reversão sexual em cada repetição

\begin{tabular}{lcc}
\hline Trat & S\% & RS\% \\
\hline T0-1 & 28.833 & 0.86 \\
T0-2 & 24.333 & 0.92 \\
T0-3 & 26.500 & 0.96 \\
T50-1 & 38.500 & 0.96 \\
T50-2 & 39.167 & 0.76 \\
T50-3 & 36.000 & 0.94 \\
T100-1 & 46.167 & 0.84 \\
T100-2 & 45.833 & 0.90 \\
T100-3 & 40.333 & 0.96 \\
T200-1 & 68.500 & 0.82 \\
T200-2 & 60.000 & 0.92 \\
T200-3 & 56.667 & 0.94 \\
T400-1 & 63.167 & 0.96 \\
T400-2 & 64.667 & 0.92 \\
T400-3 & 61.500 & 0.84 \\
T600-1 & 62.000 & 0.94 \\
T600-2 & 60.500 & 0.92 \\
T600-3 & 62.833 & 0.82 \\
T800-1 & 62.500 & 0.90 \\
T800-2 & 59.667 & 0.90 \\
T800-3 & 62.667 & 0.94 \\
T1000-1 & 74.167 & 0.86 \\
T1000-2 & 66.000 & 0.96 \\
T1000-3 & 63.500 & 0.88 \\
\hline
\end{tabular}




\section{"Print outs" dos procedimentos estatisticos}

Modelo estatístico de interação e decomposição da interação

General Linear Models Procedure

$\begin{array}{ccc}\text { Class } & \text { Level } & \text { Information } \\ \text { Class } & \text { Leveis } & \text { Values }\end{array}$

TRAT

8

0501002004006008001000

DATA

0102030

Number of observations in data set $=96$

General Linear Models Procedure

Dependent Variable: PESO

Sum of Mean

\begin{tabular}{llllll}
\hline Source & DF & Squares & Square & F Value & Pr $>$ F \\
\hline Model & 31 & 2148711.9 & 69313.3 & 3401.35 & 0.0001 \\
Error & 64 & 1304.2 & 20.4 & & \\
Corrected Total & 95 & 2150016.1 & & & \\
\hline
\end{tabular}

\begin{tabular}{|c|c|c|c|c|c|}
\hline R-Square & & V. & Root MSE & \multicolumn{2}{|c|}{ PESO Mean } \\
\hline 0.999393 & \multicolumn{2}{|c|}{4.253953} & 4.5142 & \multicolumn{2}{|c|}{106.12} \\
\hline Source & DF & Type I SS & Mean Square & F Value & $\operatorname{Pr}>F$ \\
\hline TRAT & 7 & 24024.4 & 3432.1 & 168.42 & 0.0001 \\
\hline DATA & 3 & 2072083.6 & 690694.5 & 33893.88 & 0.0001 \\
\hline TRAT*DATA & 21 & 52603.9 & 2504.9 & 122.92 & 0.0001 \\
\hline & $\mathrm{DF}$ & Type III SS & Mean Square & F Value & $\operatorname{Pr}>F$ \\
\hline TRAT & 7 & 24024.4 & 3432.1 & 168.42 & 0.0001 \\
\hline DATA & 3 & 2072083.6 & 690694.5 & 33893.88 & 0.0001 \\
\hline TRAT*DATA & 21 & 52603.9 & 2504.9 & 122.92 & 0.0001 \\
\hline
\end{tabular}

General Linear Models Procedure

Least Squares Means

TRAT*DATA Effect Sliced by DATA for PESO

Sum of Mean

\begin{tabular}{cccccc}
\hline DATA & DF & Squares & Square & F Value & $\operatorname{Pr}>\mathrm{F}$ \\
\hline 0 & 7 & $3.883917 \mathrm{E}-26$ & $5.548453 \mathrm{E}-27$ & $2.72 \mathrm{E}-28$ & 1.0000 \\
10 & 7 & 0.475982 & 0.067997 & 0.00334 & 1.0000 \\
20 & 7 & 1326.240883 & 189.462983 & 9.2974 & 0.0001 \\
30 & 7 & 75302 & 10757 & 527.9 & 0.0001 \\
\hline
\end{tabular}




\begin{tabular}{cccc}
\multicolumn{4}{c}{ General Linear Models Procedure } \\
Class & Level & Information \\
Class & Levels & Values \\
TRAT & 8 & 0501002004006008001000 \\
& DATA & 4 & 0102030 \\
Number of observations in data set $=96$
\end{tabular}

General Linear Models Procedure

Dependent Variable: COMPRIMENTO TOTAL

Sum of Mean

\begin{tabular}{|c|c|c|c|c|c|}
\hline Source & $\mathrm{DF}$ & Squares & Square & F Value & $\operatorname{Pr}>F$ \\
\hline Model & 31 & 6157.2663 & 198.6215 & 824.04 & 0.0001 \\
\hline Error & 64 & 15.4262 & 0.2410 & & \\
\hline Corrected Total & 95 & 6172.6925 & & & \\
\hline R-Square & &. $\mathrm{V}$. & Root MSE & $\mathrm{COM}$ & Mean \\
\hline 0.997501 & & 6958 & 0.4910 & & \\
\hline Source & DF & Type I SS & Mean Square & F Value & $\operatorname{Pr}>F$ \\
\hline TRAT & 7 & 63.3264 & 9.0466 & 37.53 & 0.0001 \\
\hline DATA & 3 & 6021.1296 & 2007.0432 & 8326.79 & 0.0001 \\
\hline TRAT*DATA & 21 & 72.8103 & 3.4672 & 14.38 & 0.0001 \\
\hline Source & $\mathrm{DF}$ & Type III SS & Mean Square & F Value & $\operatorname{Pr}>F$ \\
\hline TRAT & 7 & 63.3264 & 9.0466 & 37.53 & 0.0001 \\
\hline DATA & 3 & 6021.1296 & 2007.0432 & 8326.79 & 0.0001 \\
\hline TRAT ${ }^{*}$ DATA & 21 & 72.8103 & 3.4672 & 14.38 & 0.0001 \\
\hline
\end{tabular}

General Linear Models Procedure Least Squares Means

TRAT*DATA Effect Sliced by DATA for COMP Sum of Mean

\begin{tabular}{cccccc}
\hline DATA & DF & Squares & Square & F Value & $\operatorname{Pr}>\mathrm{F}$ \\
\hline 0 & 7 & $3.50401 \mathrm{E}-28$ & $5.005729 \mathrm{E}-29$ & $2.08 \mathrm{E}-28$ & 1.0000 \\
10 & 7 & 0.873670 & 0.124810 & 0.5178 & 0.8179 \\
20 & 7 & 20.186051 & 2.883722 & 11.9639 & 0.0001 \\
30 & 7 & 115.076960 & 16.439566 & 68.2042 & 0.0001 \\
\hline
\end{tabular}


Non-Linear Least Squares Summary Statistics Dependent Variable SOBREVIVÊNCIA

\begin{tabular}{cccc}
\hline Source & DF & Sum of Squares & Mean Square \\
\hline Regression & 1 & 71817.169041 & 71817.169041 \\
Residual & 23 & 671.951516 & 29.215283 \\
Uncorrected Total & 24 & 72489.120557 & \\
\hline \multicolumn{5}{c}{} & & 4860.847724 \\
\hline (Corrected Total) & 23 & & \\
\hline
\end{tabular}

NOTE: The Jacobian is singular.

Non-Linear Least Squares Summary Statistics Dependent Variable SOBREVIVÊNCIA

\begin{tabular}{cccc}
\hline Source & DF & Sum of Squares & Mean Square \\
\hline Regression & 2 & 71735.665565 & 35867.832783 \\
Residual & 22 & 753.454992 & 34.247954 \\
Uncorrected Total & 24 & 72489.120557 & \\
\hline & & & \\
\hline (Corrected Total) & 23 & 4860.847724 \\
\hline
\end{tabular}

NOTE: The Jacobian is singular. 


$$
\begin{aligned}
& \text { Analysis of Variance Procedure } \\
& \text { Class Level Information } \\
& \text { Class Levels Values }
\end{aligned}
$$

TRAT $\quad 8 \quad 0501002004006008001000$

Number of observations in data set $=24$

Analysis of Variance Procedure

Dependent Variable: REVERSÃO SEXUAL

Sum of Mean

\begin{tabular}{lccccc}
\hline Source & DF & Squares & Square & F Value & $\operatorname{Pr}>F$ \\
\hline Model & 7 & 0.00198333 & 0.00028333 & 0.07 & 0.9993 \\
Error & 16 & 0.06720000 & 0.00420000 & & \\
Corrected Total & 23 & 0.06918333 & & & \\
\hline \multicolumn{7}{r}{ R-Square } & C.V. & Root MSE & RS Mean \\
\hline 0.028668 & 7.194162 & 0.064807 & 0.90083333 \\
\hline
\end{tabular}

Analysis of Variance Procedure Dependent Variable: REVERSÃO SEXUAL

\begin{tabular}{cccccc}
\hline Source & DF & Anova SS & Mean Square & F Value & Pr $>$ F \\
\hline TRAT & 7 & 0.00198333 & 0.00028333 & 0.07 & 0.9993 \\
\hline
\end{tabular}

Analysis of Variance Procedure

Dependent Variable: SOBREVIVÊNCIA

Sum of Mean

\begin{tabular}{lccccc}
\hline Source & DF & Squares & Square & F Value & $\operatorname{Pr}>F$ \\
\hline Model & 7 & 4673.473204 & 667.639029 & 57.01 & 0.0001 \\
Error & 16 & 187.374519 & 11.710907 & & \\
Corrected Total & 23 & 4860.847724 & & & \\
\hline
\end{tabular}

\begin{tabular}{llll}
\hline R-Square & C.V. & Root MSE & SOB Mean \\
\hline 0.961452 & 6.446689 & 3.422120 & 53.0833750 \\
\hline
\end{tabular}

Analysis of Variance Procedure

Dependent Variable: SOBREVIVÊNCIA

\begin{tabular}{llllll}
\hline Source & DF & Anova SS & Mean Square & F Value & Pr $>$ F \\
\hline TRAT & 7 & 4673.473204 & 667.639029 & 57.01 & 0.0001 \\
\hline
\end{tabular}


Analysis of Variance Procedure

Tukey's Studentized Range (HSD) Test for variable: REVERSÃO SEXUAL

NOTE: This test controls the type I experimentwise error rate, but generally has a higher type II error rate than REGWQ.

Alpha $=0.05 \mathrm{df}=16 \mathrm{MSE}=0.0042$

Critical Value of Studentized Range $=4.896$

Minimum Significant Difference $=0.1832$

Means with the same letter are not significantly different.

\begin{tabular}{cccc}
\hline Tukey Grouping & Mean & N & TRAT \\
\hline A & 0.9133 & 3 & 0 \\
A & 0.9133 & 3 & 800 \\
A & 0.9067 & 3 & 400 \\
A & 0.9000 & 3 & 100 \\
A & 0.9000 & 3 & 1000 \\
A & 0.8933 & 3 & 600 \\
A & 0.8933 & 3 & 200 \\
A & 0.8867 & 3 & 50 \\
\hline
\end{tabular}

Analysis of Variance Procedure

Tukey's Studentized Range (HSD) Test for variable: SOBREVIVÊNCIA

NOTE: This test controls the type I experimentwise error rate, but generally has a higher type II error rate than REGWQ.

$$
\text { Alpha }=0.05 \quad \mathrm{df}=16 \quad \mathrm{MSE}=11.71091
$$

Critical Value of Studentized Range $=4.896$

Minimum Significant Difference $=9.6738$

Means with the same letter are not significantly different.

\begin{tabular}{cccc}
\hline Tukey Grouping & Mean & N & TRAT \\
\hline A & 67.889 & 3 & 1000 \\
A & 63.111 & 3 & 400 \\
A & 61.778 & 3 & 600 \\
A & 61.722 & 3 & 200 \\
A & 61.611 & 3 & 800 \\
B & 44.111 & 3 & 100 \\
B & 37.889 & 3 & 50 \\
C & 26.555 & 3 & 0 \\
\hline
\end{tabular}

